ISABEL PEIXOTO TORTAMANO

EFICÁCIA ANESTÉSICA DA ARTICAÍNA E DA LIDOCAÍNA EM PACIENTES COM PULPITE IRREVERSÍVEL

São Paulo 
ISABEL PEIXOTO TORTAMANO

\section{EFICÁCIA ANESTÉSICA DA ARTICAÍNA E DA LIDOCAÍNA EM PACIENTES COM PULPITE IRREVERSÍVEL}

Tese apresentada à Faculdade de Odontologia da Universidade de São Paulo, para concurso de Livre Docente da Disciplina de Clínica Integrada do Departamento de Estomatologia da Faculdade de Odontologia da Universidade de São Paulo.

São Paulo 


\section{FOLHA DE APROVAÇÃO}

Tortamano IP. Eficácia anestésica da articaína e da lidocaína em pacientes com pulpite irreversível. [Tese de Livre - Docência]. São Paulo: Faculdade de Odontologia da USP; 2007.

São Paulo, / / /2007

\section{Banca Examinadora}

1) $\operatorname{Prof}(a) \cdot \operatorname{Dr}(a)$

Titulação:

Julgamento:

Assinatura:

2) $\operatorname{Prof}(a) \cdot \operatorname{Dr}(a)$.

Titulação:

Julgamento:

Assinatura:

3) $\operatorname{Prof}(a) \cdot \operatorname{Dr}(a)$.

Titulação:

Julgamento:

Assinatura:

4) $\operatorname{Prof}(a) \cdot \operatorname{Dr}(a)$.

Titulação:

Julgamento:

Assinatura:

5) $\operatorname{Prof}(a) \cdot \operatorname{Dr}(a)$.

Titulação:

Julgamento:

Assinatura: 
A Deus, por tudo...

Aos meus pais, Osvaldo e Laurinda, e a minha tia, Dinda, pela minha formação e, agradeço não apenas por me ensinarem o caminho, mas por terem sempre deixado seu próprio rastro como exemplo de vida.

Aos meus sobrinhos, Marina, Guilherme, Natália e Mariana e as minhas irmãs Rossana e Daniela pelo apoio incondicional e por me darem a certeza de que vale a pena lutar pelos nossos ideais.

Ao meu marido, Pedro, pelo apoio, hoje, presente, e aos meus filhos, Pedro e Lucas, peço desculpas pela minha ausência, e agradeço por preencherem totalmente a minha vida. 
Ao Prof. Dr. Rodney Garcia Rocha pela oportunidade e o apoio que me foi concedido. 


\section{AGRADECIMENTOS}

Aos pacientes voluntários que concordaram em participar nessa pesquisa, sem eles e sem colaboração deles, seria impossível a realização desse trabalho.

Aos professores da Disciplina de Clínica Integrada Waldir Jorge, Mário Sérgio, José Leonardo, Carlos e Flávio e de um modo muito especial às professoras do Setor de Urgência, Maria Aparecida, Sibele e Inês pela agradável convivência profissional e pela amizade.

Às funcionárias do Setor de Urgência, Jady, Hayde e Joana, pela compreensão durante a realização da parte clínica experimental dessa pesquisa.

Aos meus orientados, Marcelo e Carina, e aos estagiários do Setor de Urgência, Gláucio e Ciliana, pelo auxílio nas traduções dos artigos científicos.

À amiga Vilma Vieira, secretária da Disciplina de Clínica Integrada por sua competência profissional e pela amizade dedicada em tantas ocasiões.

À secretária do Departamento de Estomatologia, Vera pelas suas valiosas informações, fruto da sua experiência e competência.

À secretária do Setor de Urgência, Regina, sempre solícita a nos atender de uma maneira muito gentil.

A todos os funcionários da FOUSP, em especial ao Edson, secretário da Disciplina de Cirurgia que, direta ou indiretamente, colaboraram para que este trabalho se realizasse.

Aos colegas da biblioteca, Cidinha, Luzia, Vânia, Graice, Sueli, Paschoal e Fernando ao auxílio sempre presente de forma amável e simpática. 
Tortamano IP. Eficácia anestésica da articaína e da lidocaína em pacientes com pulpite irreversível. [Tese de Livre - Docência]. São Paulo: Faculdade de Odontologia da USP; 2007.

\section{RESUMO}

O objetivo deste estudo foi comparar a eficácia anestésica da articaína 4\% com a lidocaína 2\%, ambas associadas à epinefrina 1:100.000, em pacientes com pulpite irreversível em dentes posteriores mandibulares durante procedimento de pulpectomia. Quarenta voluntários do Setor de Urgência da Faculdade de Odontologia da Universidade de São Paulo receberam, aleatoriamente, 3,6ml de um dos anestésicos locais para o bloqueio convencional do nervo alveolar inferior e 3,6 ml da mesma solução na injeção complementar no ligamento periodontal em caso de falha do bloqueio. O sinal subjetivo de anestesia do lábio, a presença de anestesia pulpar e ausência de dor durante o procedimento de pulpectomia foram avaliadas, respectivamente, por indagação ao paciente, através do aparelho estimulador pulpar elétrico ("pulptest") e por uma escala de dor verbal. A análise estatística foi realizada através do teste Qui-quadrado e o teste exato de Fisher. O sinal subjetivo da anestesia no lábio foi relatado por todos os pacientes. A articaína apresentou maior índice de ausência de dor (65\%) e a lidocaína maior índice de anestesia pulpar (70\%) após o bloqueio do nervo alveolar inferior. A lidocaína apresentou maior índice de anestesia pulpar (90,9\%) e maior índice de ausência de dor $(81,8 \%)$ após a injeção no ligamento periodontal. Essas diferenças não foram estatisticamente significantes. As duas soluções anestésicas locais se comportam de forma semelhante e não apresentam índices de sucesso anestésico aceitável em pacientes com pulpite irreversível em dentes posteriores mandibulares.

Palavras-Chave: Articaína; lidocaína; pulpite irreversível; bloqueio do nervo alvolar inferior; injeção complementar 
Tortamano IP. Anesthetic efficacy of articaine and lidocaine in patients with irreversible pulpitis. [Tese de Livre - Docência]. São Paulo: Faculdade de Odontologia da USP; 2007.

\section{ABSTRACT}

The aim of this study was to compare the efficacy of anesthesia between $4 \%$ articaine and $2 \%$ lidocaine, both associates with 1:100.000 epinephrine, in patients with irreversible pulpitis in mandibular posterior teeth during pulpectomy procedure.

Forty volunteers of the Sector of Urgency of the School of Dentistry of the University of São Paulo randomized received 3,6ml of one of the two local anaesthesics for the inferior alveolar nerve blocks and $3,6 \mathrm{ml}$ of the same solution in the supplemental injection in the periodontal ligament in case of fault of the blockade. The subjective sign of the lip anesthesia; the presence of pulpar anesthesia and absence of pain during the pulpectomy procedure had been evaluated, respectively, by the patient complaint, by the pulpar electric estimulador device ("pulptest") and by a verbal pain scale. The statistics analysis was done by Qui-square tests and Fisher test. The subjective sign of lip anesthesia was report by all patients. Articaine shown the higher score of pain absence (65\%) and lidocaine the higher score of pulpar anesthesia (70\%) after the inferior alveolar nerve blockade. Lidocaine shown the higher scores of pulpar anesthesia (90.9\%) and pain absence (81.8\%) after the injection in the periodontal ligament. There was no signifcant statistic difference between these two scores. The two local anesthetics solutions shown similar results, and they do not

present an acceptable success rate of anaesthesia in patients with irreversible pulpitis in mandibular posterior teeth.

Key-works: Articaine; lidocaine; irreversible pulpitis; inferior alveolar nerve block; supplemental injection 


\section{LISTA DE ILUSTRAÇÕES}

Figura 4.1 - Aparelho estimulador pulpar elétrico Vitality Scanner $2006^{\circledR}$, SybronEndo, CA, USA ................................................ 26

Figura 5.1 - Gráfico de barras das porcentagens de ocorrências das categorias das respostas ao "pulptest" nos grupos articaína e lidocaína - após bloqueio do NAI

Figura 5.2 - Gráfico de barras das porcentagens de ocorrências das categorias da dor nos grupos articaína e lidocaína - após bloqueio do NAI ........... 35

Figura 5.3 - Gráfico de barras das porcentagens de ocorrências das categorias dos locais onde a dor foi relatada nos grupos articaína e lidocaína após bloqueio do NAI

Figura 5.4 - Gráfico de barras das porcentagens de ocorrências das categorias das respostas ao "pulptest" nos grupos articaína e lidocaína - após injeção no ligamento periodontal.

Figura 5.5 - Gráfico de barras das porcentagens de ocorrências das categorias da dor nos grupos articaína e lidocaína - após injeção no ligamento periodontal 


\section{LISTA DE TABELAS}

Tabela 5.1 - Estatísticas descritivas para idade nos grupos articaína e lidocaína.. 32

Tabela 5.2 - Distribuições das freqüências e porcentagens dos dentes em cada grupo e total

Tabela 5.3 - Distribuições das freqüências e porcentagens das respostas ao "pulptest" nos dois grupos - após bloqueio do NAI

Tabela 5.4 - Distribuições das freqüências e porcentagens da dor nos dois grupos após bloqueio do NAl

Tabela 5.5 - Distribuições das freqüências e porcentagens dos locais onde a dor foi relatada nos dois grupos - após bloqueio do NAI

Tabela 5.6 - Distribuições das freqüências e porcentagens das respostas ao "pulptest" nos dois grupos - após injeção no ligamento periodontal ...32

Tabela 5.7 - Distribuições das freqüências e porcentagens da dor nos dois grupos após injeção no ligamento periodontal 


\section{LISTA DE ABREVIATURA E SIGLAS}

$\begin{array}{ll}\text { NAI } & \text { nervo alveolar inferior } \\ \text { PDL } & \text { injeção no ligamento periodontal } \\ \text { IO } & \text { injeção intraóssea } \\ \text { pulptest } & \text { testador (estimulador) pulpar elétrico } \\ \mathrm{mm} & \text { milímetros } \\ \mathrm{min} & \text { minutos } \\ \mathrm{ml} & \text { mililitro } \\ \mathrm{mg} & \text { miligrama } \\ \mathrm{Kg} & \text { quilograma }\end{array}$




\section{LISTA DE SÍMBOLOS}

marca registrada 


\section{SUMÁRIO}

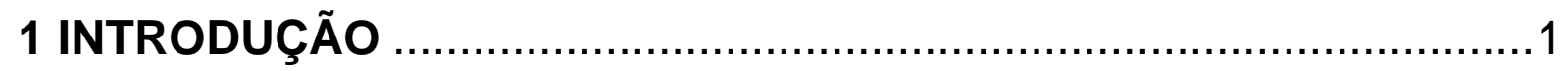

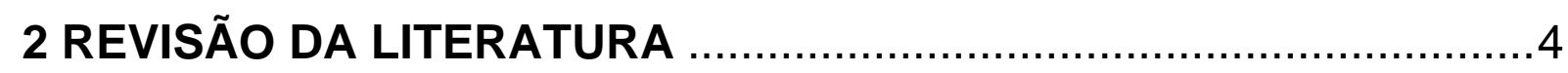

2.1 Bloqueio do nervo alveolar inferior e sucesso da anestesia $\quad . \ldots \ldots \ldots \ldots \ldots \ldots . \ldots \ldots$

2.2 Bloqueio do nervo alveolar inferior e pulpite irreversível .......................12

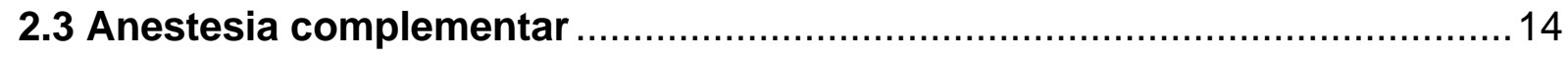

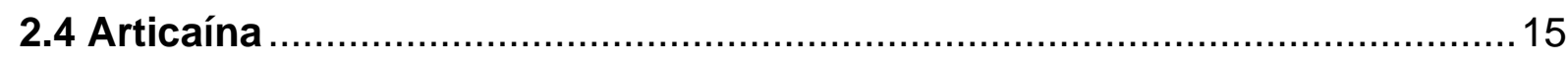

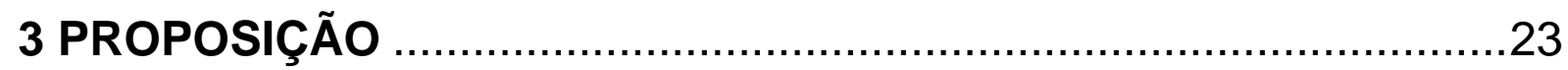

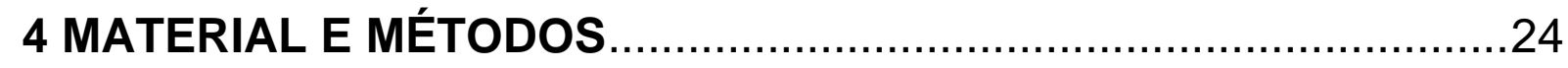

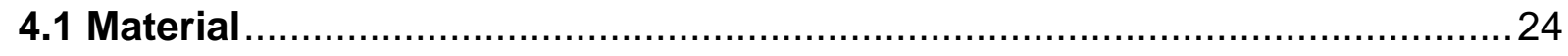

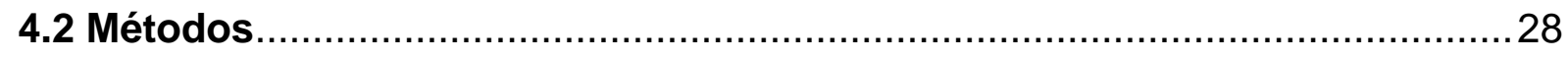

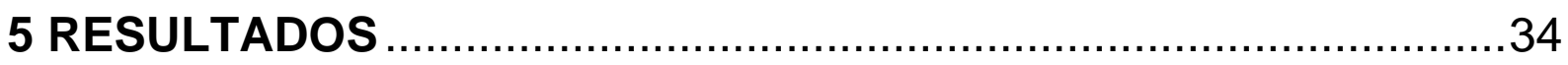

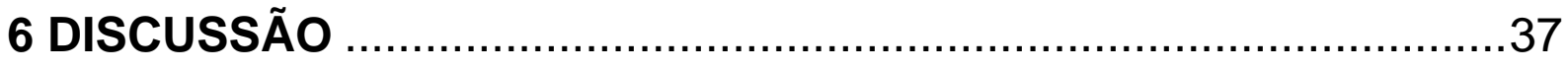

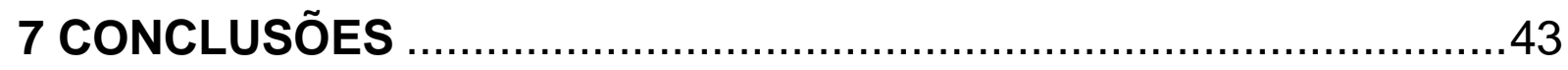

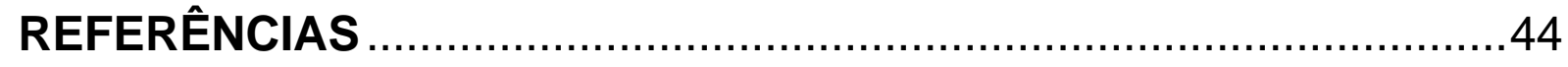

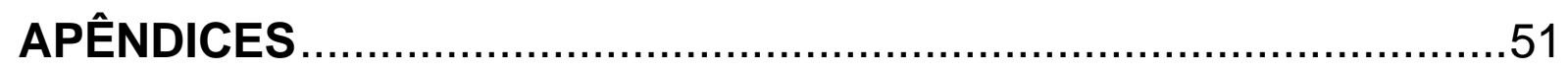

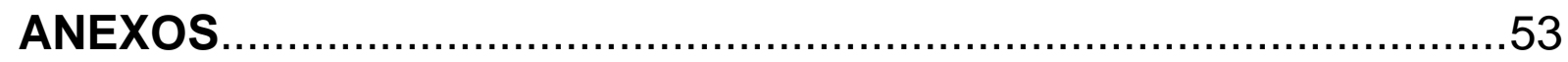




\section{INTRODUÇÂO}

O bloqueio do nervo alveolar inferior é a técnica de injeção mandibular frequentemente usada para o alcance da anestesia local em odontologia.

Entretanto, o bloqueio do nervo alveolar inferior nem sempre resulta numa anestesia pulpar bem sucedida. Mesmo quando as técnicas apropriadas são usadas, estudos clínicos mostram índices de falhas significativos.

Nos dentes posteriores mandibulares com diagnóstico de pulpite irreversível as falhas do bloqueio do nervo alveolar inferior apresentam índices ainda mais elevados, sendo esse um problema clínico comum em odontologia. Com a finalidade de minimizar a dor do paciente, o cirurgião-dentista tem de utilizar as técnicas anestésicas complementares. Estas incluem a injeção do ligamento periodontal, a injeção intraóssea, a injeção intraseptal e a injeção intrapulpar.

Ao longo dos anos, vários anestésicos locais têm surgido, mas nem um superou a lidocaína em termos de eficácia e segurança. A lidocaína foi introduzida na odontologia em 1948 e até hoje é considerada o "padrão - ouro", ou seja, a droga à qual todos os novos anestésicos locais são comparados.

Entre os novos anestésicos locais, destaca-se a articaína, a qual foi introduzida recentemente no Brasil e nos Estados Unidos. É o anestésico mais utilizado no Canadá e em vários países europeus, principalmente na Alemanha, onde corresponde a $80 \%$ dos anestésicos locais vendidos para uso odontológico. 
Como a articaína é uma droga relativamente nova tem sido sujeita a muita discussão entre os cirurgiões-dentistas que apontam algumas características boas (início de ação rápido e elevadas taxas de sucesso) e algumas ruins (risco aumentado de parestesia).

Apesar de algumas vantagens da articaína sobre a lidocaína, as pesquisas clínicas não têm mostrado que a articaína é estatisticamente superior na eficácia do bloqueio no nervo alveolar inferior, assim como também, na anestesia infiltrativa. Exceção se faz a poucos estudos.

A investigação da articaína em pacientes com pulpite irreversível é também bastante reduzida e não há nenhuma que utilize a articaína na injeção do ligamento periodontal como anestesia complementar ao bloqueio do nervo alveolar inferior, com o uso de seringas e técnicas convencionais.

Por ser um problema clínico comum e parecer que anos de experiência não influenciam o índice de falhas do bloqueio do nervo alveolar inferior e, portanto, a experiência não conduz para o sucesso do controle da dor, constantemente, estamos em busca de soluções, quer sejam elas, relacionadas às técnicas ou às soluções anestésicas locais. 


\section{REVISÃO DA LITERATURA}

\subsection{Bloqueio do nervo alveolar inferior e sucesso da anestesia}

O bloqueio do nervo alveolar inferior é a técnica mais frequentemente utilizada para se conseguir a anestesia local em procedimentos restauradores e cirúrgicos na mandíbula. Entretanto, o bloqueio do nervo alveolar inferior (NAI) nem sempre resulta em uma anestesia pulpar bem sucedida (NUSSTEIN, REACHER; BECK, 2002).

Esse assunto, apesar de antigo em odontologia, continua sem solução até os dias atuais. Weinstein et al. (1985) relataram que 1 entre 7 pacientes apresentaram dor durante tratamento odontológico.

Kaufman, Weinstein e Milgrom (1984) em um levantamento com 93 clínicos gerais encontraram que $90 \%$ tinham tido alguma dificuldade na anestesia em trabalhos restauradores e que falhas na anestesia ocorrem em $13 \%$ de todas as injeções, sendo a maioria delas (88\%) em bloqueios do NAI. Portanto, os resultados de sua pesquisa suportam e aceitam o fato de que, é mais difícil alcançar analgesia depois do bloqueio do NAI do que com os métodos infiltrativos. Os autores concluíram que; a análise dos resultados indicou que a falha anestésica é um problema clínico; a maioria dos profissionais relatou várias falhas anestésicas e que 
anos de experiência não influenciaram no índice da falhas e a experiência não conduziu para mais sucesso do controle da dor.

Dagher, Yared e Machtou (1997) compararam o grau da anestesia do bloqueio do NAl, através do teste elétrico da polpa (Analytic Technology Corp. ${ }^{\circledR}$, Redmound, WA), obtido com 1,8 ml de lidocaína 2\% com diferentes concentrações de epinefrina (1:50.000, 1:80.000 e 1:100.000) em 30 adultos de maneira aleatória e duplo-cego. As três soluções com diferentes concentrações de epinefrina foram equivalentes e os autores salientaram que seus resultados concordam com os de Keelisng e Hinds ${ }^{1}$ (1963, apud DAGHER; YARED; MACHTOU, 1997), Gangarosa e Halik$^{2}$ (1967, apud DAGHER; YARED; MACHTOU, 1997) e Hander e Alberts ${ }^{3}$ (1987, apud DAGHER; YARED; MACHTOU, 1997) que falharam na demonstração do relacionamento entre a concentração do vasoconstritor e sucesso na anestesia pulpar.

Mikesell et al.(2005), aproveitando as especulações de que a articaína tem uma reputação de fornecer um efeito anestésico local melhorado (SCHERTZER; MALAMED, 2001), compararam o grau de anestesia pulpar obtido com articaína 4\% e lidocaína 2\%, ambas com epinefrina 1:100.000, no bloqueio do NAl em um estudo em que a administração das soluções foram feitas aleatoriamente, numa maneira duplo-cego e cruzado em 57 pacientes. Um verificador elétrico da polpa (Kerr, Analytic Technology Corp. ${ }^{\circledR}$, Redmond, WA) foi usado para testar a vitalidade da polpa em ciclos de 4 minutos por 60 minutos, dos pré-molares, molares e incisivos. A anestesia pulpar bem sucedida variou de $4 \%$ a $54 \%$ do incisivo central ao segundo

\footnotetext{
${ }^{1}$ Keesling GR, Hinds EC. Optimal concentration of epinephrine in lidocaine solutions. J Am Dent Assoc 1963;66:337-40.

${ }^{2}$ Gangarosa LP, Halik FJ. A clinical evaluation of local anesthetic solutions containing graded epinephrine concentrations. Arch Oral Biol 1967;12:611-21.

${ }^{3}$ Handler LE, Alberts DD. The effects of the vasoconstrictor epinephrine on the duration of pulpal anesthesia using the intraligamentary injection. J Am Dent Assoc 1987;114:807-9.
} 
molar para a solução de articaína, e de 2\% a 48\% para a lidocaína, essas diferenças não foram significantes e os autores concluíram que as soluções tiveram resultados similares.

Baseado no fato de que, o nervo milohioideo tem sido frequentemente apontado como um possível causador do fracasso do bloqueio do NAl em endodontia, Clarck, Reader e Meyers (1999), compararam, em 30 pacientes, o grau de anestesia pulpar obtido entre três situações: o bloqueio do nervo milohioideo associado ao bloqueio do NAI; uma simulação do bloqueio do nervo milohioideo associada ao bloqueio do NAl e, finalmente, ao bloqueio do nervo milohioideo associado a uma simulação do bloqueio do NAI. O anestésico local utilizado foi o cloridrato de lidocaína 2\% associado à epinefrina 1:100.000 na dose de 1,8 ml para o bloqueio do nervo milohioideo e na dose de $3,6 \mathrm{ml}$ para o bloqueio do NAI. O bloqueio no nervo milohioideo quando injetado separadamente não proveu anestesia pulpar nos dentes mandibulares, e quando administrado associado ao bloqueio do NAI não aumentou significativamente a anestesia pulpar.

Meechan et al. (2006) baseado na suposta inervação colateral e ao fato de que a combinação da infiltração vestibular associada à lingual foi mais eficaz do que somente a infiltração vestibular em dentes mandibulares anteriores e que nenhum estudo similar foi relatado para os dentes mandibulares posteriores, compararam a eficácia de somente infiltração vestibular $(1,8 \mathrm{ml})$ com a infiltração anestésica vestibular $(0,9 \mathrm{ml})$ associada à lingual $(0,9 \mathrm{ml})$ para os primeiros molares permanentes mandibulares, utilizando um verificador da polpa (Analytic Technology ${ }^{\circledR}$, Redmound, WA, EUA) e a lidocaína 2\% com epinefrina 1:100.000 em um experimento duplocego e aleatório em 31 voluntários adultos. Não observaram nenhuma evidência de 
que somente infiltração vestibular ou a infiltração vestibular associada à lingual diferem em suas eficácias para os molares permanentes mandibulares.

Kanaa et al. (2006) afirmaram que o sucesso do bloqueio NAI pode variar de $30 \%$ a $97 \%$ e que muitos fatores podem influenciar no sucesso: anatomia, patologia, farmacologia e psicologia, no entanto, a influência da velocidade da injeção nunca havia sido testada. Sendo assim, um estudo duplo-cego e aleatório em uma amostra de 38 pacientes foi projetado para comparar a eficácia do bloqueio do NAI lento (60 seg) e rápido (15 seg) de 2,0 ml de lidocaína com 1:80.000 de epinefrina . O bloqueio lento do NAI produziu mais episódios de respostas negativas ao estímulo elétrico máximo da polpa em primeiros molares, pré-molares e incisivos laterais que na injeção rápida. O desconforto da injeção também foi significantemente menor. Os autores sugeriram que este teste deveria ser repetido em dentes com inflamação pulpar onde uma maior profundidade de anestesia é exigida para bloquear sinais aferentes dos tecidos inflamados.

Lai et al. (2006) afirmaram que o bloqueio mandibular é o mais usado para promover a anestesia local na mandíbula e nem sempre resulta em anestesia bem sucedida e que as falhas variam de $15 \%$ a $45 \%$. Para os autores, essas discrepâncias entre os resultados e as comparações dos resultados de estudos prévios são limitadas. Eles alegam ser devido à falta de padronização das técnicas para medir o bloqueio mandibular, a variabilidade na interpretação da dor entre pacientes e a falta de parâmetros objetivos para a avaliação clínica. Eles defenderam o uso do testador pulpar elétrico por ser um estímulo padrão e seguro e baseado nos estudos de McDaniel, Rowe e Charbeneau ${ }^{5}$ (1973, apud LAl et al.,

5 McDaniel KF, Rowe NH, Charbeneau GT. Tissue response to an electric pulp tester. J Prosthet Dent 1973;29:84-7. 
2006), que comprovaram que o teste prolongado da polpa não causa dano histológico à polpa.

A técnica usada para o bloqueio mandibular por Lai et al. (2006) foi a técnica padrão proposta por Malamed ${ }^{6}$ (2004, apud LAl et al., 2006) e a solução utilizada foi a lidocaína 2\% com epinefrina 1:100.000 com uma dose total de 2,1 ml. A taxa de sucesso da anestesia pulpar foi de 5,7\% para o incisivo central, 38,2\% para o canino, 55,3\% para o primeiro pré-molar e $90,2 \%$ para o primeiro molar. Afirmaram que a latência (início) da anestesia do lábio é mais rápida do que a pulpar e uma anestesia bem sucedida no lábio não indica necessariamente o sucesso da anestesia pulpar. A anestesia pulpar foi mais lenta para os dentes anteriores do que para os dentes posteriores depois do bloqueio mandibular, confirmando a teoria do núcleo central proposta por De Jong $^{7}$ (1970, apud LAl et al., 2006), a qual sugere que os nervos que suprem as estruturas distais ocupam uma posição central no núcleo do feixe do nervo, enquanto áreas proximais são supridas pelos nervos posicionados perifericamente. Sendo assim as fibras mais próximas da superfície do nervo (feixe de proteção) inervam a área de molar enquanto as fibras do centro do nervo (feixe do núcleo) inervam os incisivos centrais e laterais. Outro fator que pode explicar a falta da anestesia profunda nos incisivos é a inervação acessória, porém os autores sugerem que mais pesquisas deverão ser realizadas em relação a esses fatores.

Rosenberg et al. (2007) em um experimento duplo-cego e ao acaso compararam a articaína 4\% e lidocaína 2\%, as duas com 1:100.000 de epinefrina, quando usada como anestesia complementar a um bloqueio do NAI em 26 dentes

6 Malamed SF. Techiniques of mandibular anesthesia. In:Malamed SF. Handbook of local anesthesia. St Louis: Mosby; 2004. p.227-53.

DeJong RH. Sistemic effects of local anesthetics. In: DeJong RH, editor. Physiology and pharmacology of local anesthesia. Springfield: CharlesC Thomas; 1970. p.118-22. 
posteriores mandibulares ou quando usada como anestesia complementar a uma injeção infiltrativa em 22 dentes posteriores maxilares. A anestesia complementar foi uma injeção infiltrativa vestibular na dose de 1,8 ml. A escala de dor VAS foi usada para avaliar a resposta dos pacientes para a dor depois da injeção complementar. A diferença não foi significante entre a média da VAS para a articaína $(15,28)$ e a lidocaína $(19,70)$ e nem entre a escala VAS para os dentes maxilares e mandibulares.

\subsection{Bloqueio do nervo alveolar inferior e pulpite irreversível}

As falhas na realização da analgesia, principalmente em dentes com pulpite irreversível, são bastante elevadas, variam de 44\% a 81\% (NUSSTEIN et al., 1998; REISMAN et al., 1997; KENNEDY et al., 2003).

Para Taintor e Biesterfeld (1989) há muitas razões para o insucesso do bloqueio do NAI, porém as teorias mais populares incluem: inflamação na área que causa as mudanças de $\mathrm{pH}$ do tecido impedindo o adequado funcionamento da solução anestésica; alterações nos tecidos dos nervos em conseqüência da inflamação impedindo a anestesia apropriada e inervações aberrantes não acessíveis aos anestésicos.

Walton e Torabinejad (1992) enfatizaram que a terapia do canal radicular tem uma péssima reputação. Os autores atribuíram esse fato à mídia pelos relatos de dores severas e à inabilidade dos profissionais de obterem anestesia profunda. Além do que salientaram que pacientes apreensivos em combinação com a inflamação 
tecidual apresentam menor limiar de dor diminuindo a eficácia anestésica. Eles afirmaram que a primeira escolha para a anestesia dental é a administração do bloqueio convencional do NAI ou infiltração. Caso a anestesia profunda não ocorrer utilizam-se técnicas complementares como a infiltração lingual, a injeção do ligamento periodontal (PDL) ou anestesia intrapulpar. Devido às infiltrações nem sempre serem eficazes, a injeção do ligamento periodontal e a intrapulpar são preferidas. A injeção do ligamento periodontal, segundo os autores, é melhor do que a injeção intrapulpar, pois não é dolorosa, é segura e usualmente efetiva. A injeção intrapulpar é limitada e pode ser desconfortável. Os autores ainda recomendam a administração de lidocaína 2\% com epinefrina para anestesias convencionais e complementares e para tratamentos de emergências e procedimentos longos, administração de bupivacaína 0,5\%.

Já para Patocnik e Bajrovic (1999) quando técnicas apropriadas são usadas, estudos clínicos mostraram que as falhas do bloqueio do NAl são de aproximadamente $30 \%$ a $45 \%$ em molares saudáveis e em molares com inflamação aguda a frequência dessas falhas é ainda mais alta. Este parece ser um problema clínico comum. As razões para essas falhas não são inteiramente compreendidas, mas podem ser resumidas como segue: a) fator ansiedade que abaixa diretamente o limiar de dor, fatores psicológicos, tais como personalidade e a expectativa influenciando a percepção de dor; b) a teoria da inervação acessória dos molares mandibulares não pode ser desprezada, no entanto, a taxa de falhas do bloqueio do nervo alveolar inferior excede a incidência dessa inervação; c) não parece haver diferenças significativas entre as taxas de falhas e os agentes anestésicos, assim como com sua concentração e volume; e finalmente, d) os neurônios e seus axônios de tecidos inflamados podem alterar o potencial de repouso e o limiar de 
excitabilidade, portanto mudanças químicas que se estendem em todas as fibras afetadas do nervo podem alterar a sua capacidade de ser anestesiada. Todas essas razões, segundo os autores, podem explicar somente em parte a taxa de falhas do bloqueio do NAI. Pesquisas futuras, especialmente relacionadas à inflamação do nervo e ao desenvolvimento de novos anestésicos locais são necessárias para melhorar a efetividade do bloqueio do NAI.

Algumas inovações nas técnicas para tentar melhorar o sucesso do bloqueio padrão do nervo alveolar inferior em dentes com pulpite ireversíveis foram propostas por Bigby et al. (2007) e por Kennedy et al. (2003):

Bigby et al. (2007) adicionou 36 mg de meperidina à 36 mg de lidocaína com $18 \mu \mathrm{g}$ de epinefrina e comparou à injeção de 36 mg de lidocaína com 18$\mu \mathrm{g}$ de epinefrina, dose proporcional a 2 tubetes, em bloqueios convencionais do NAI e afirmaram não ter melhora significativa na taxa de sucesso em cima da solução convencional de lidocaína.

Kennedy et al. (2003) propôs uma técnica de agulha rotativa bidericional computadorizada na tentativa de depositar 2,8 $\mathrm{ml}$ de lidocaína $2 \%$ com epinefrina 1:100.000 o mais próximo possível ao nervo alveolar inferior e comparou com a técnica padrão e concluíram que para dentes posteriores mandibulares com pulpite irreversível nenhum bloqueio obteve uma taxa satisfatória de sucesso.

Um estudo prospectivo, duplo-cego e aleatório desenvolvido por Clafey et al. (2004) comparou a eficácia anestésica no bloqueio convencional de 2,2 $\mathrm{ml}$ da articaína 4\% à lidocaína 2\%, ambas com epinefrina na concentração de 1:100.000, em 72 pacientes com pulpite irreversível em dentes posteriores mandibulares. 0 sucesso foi definido como nehuma ou leve dor ao acesso endodôntico ou 
instrumentação inicial. A porcentagem de sucesso para a articaína foi de $24 \%$ e para a lidocaína $23 \%$ e essas diferenças não foram estatisticamente significantes.

\subsection{Anestesia complementar}

Quando as infiltrações locais e os bloqueios regionais dos nervos não fornecem o nível necessário de anestesia para controle da dor, as técnicas complementares estão disponíveis. Estas incluem a injeção do ligamento periodontal (PDL), a injeção intraóssea (IO), a injeção intraseptal e a injeção intrapulpar (MALAMED, 2005).

Segundo Taintor e Biesterfeld (1989) a injeção do PDL pode ser considerada uma injeção 10 que coloca a solução anestésica no osso através do sulco gengival enquanto a injeção intraóssea "verdadeira", datando de 1906, coloca a solução mais diretamente no ápice da raiz. A técnica da injeção IO é realizada através de uma perfuração no osso cortical e no espaço medular usando, usualmente, um motor. Uma agulha de calibre 25 ou 30 é introduzida na perfuração para a deposição da solução anestésica. Essa injeção é quase que exclusivamente para complementar um bloqueio padrão inadequado. O perigo encontra-se na possibilidade de penetrar na superfície da raiz com o motor e seu uso não é recomendado rotineiramente.

Atualmente, há um sistema de injeção intraóssea (IO) que foi introduzido no mercado com o nome de Stabident ${ }^{\circledR}$ (Fairfax Dental Inc., Miami, FL). Este sistema é composto de um perfurador manual de baixa velocidade, em que um fio sólido de calibre 27 com um chanfro na extremidade realiza um pequeno furo através do osso 
cortical e assim a solução anestésica é injetada no osso esponjoso por meio de um injetor com uma agulha de calibre 27.

Utilizando o sistema acima descrito, Reisman et al. (1997) determinaram a eficácia de uma injeção complementar de 1,8 ml de mepivacaína 3\% sem vasoconstritor ao bloqueio do NAI (1,8 ml de lidocaína 2\% com epinefrina 1:100.00) em 48 dentes posteriores inferiores com pulpite irreversível. Foi utilizado "pulptester" (Analytic Technology ${ }^{\circledR}$, Redmound, WA) para determinar a anestesia pulpar. Os pacientes que responderam positivamente ao estímulo máximo da polpa, ou negativamente, mas que sentiram dor durante o tratamento endodôntico, receberam uma injeção IO de 1,8 ml de mepivacaína 3\%. Uma segunda injeção intraóssea de mepivacaína $3 \%(1,8 \mathrm{ml})$ foi administrada se a primeira fosse mal sucedida. Os resultados mostraram que $75 \%$ dos pacientes necessitaram de uma injeção intraóssea devido à falha em obter anestesia pulpar com o bloqueio padrão, ou seja, este foi bem sucedido em $25 \%$; a primeira injeção (IO) aumentou o sucesso para $80 \%$ e uma segunda para 98\%, essas diferenças foram significantes. Em 8\% (4 casos) das injeções IO, a solução foi despejada na cavidade oral e foi considerada falha de técnica.

Parente et al. (1998) avaliou a eficácia da injeção complementar intráossea de lidocaína 2\% com epinefrina 1:100.000, utilizando o sistema Stabident ${ }^{\circledR}$ (Fairfax Dental Inc., Miami, FL) e uma escala analógica visual (VAS) em 37 pacientes com pulpite irreversível após o bloqueio padrão do NAI, na dose de 3,6 ml da mesma solução. Os autores concluíram que a injeção complementar com o Stabident foi efetiva em $91 \%$ dos pacientes avaliados.

Em outro estudo, Nusstein et al. (1998), também investigou a lidocaína a 2\% com epinefrina 1:100.000 na eficácia anestésica da injeção IO complementar com o 
sistema Stabident ${ }^{\circledR}$ (Fairfax Dental Inc., Miami, FL) em 25 dentes posteriores maxilares e 26 dentes posteriores mandibulares de 51 pacientes com pulpite irreversível. Para o bloqueio padrão do NAI e para a injeção IO complementar a dose de 1,8 $\mathrm{ml}$ foi utilizada, para a injeção infiltrativa maxilar a dose de 3,6 ml. A solução empregada em todas as anestesias foi a lidocaína 2\% com 1:100.000 de epinefrina. Os resultados demonstraram que $42 \%$ dos pacientes que responderam negativamente ao teste elétrico relataram dor durante o tratamento e necessitaram de anestesia complementar. A injeção intraóssea foi necessária em 81\% dos dentes mandibulares e $12 \%$ dos dentes maxilares devido à falha na anestesia pulpar, essa diferença foi significante. A injeção intraóssea com Stabident ${ }^{\circledR}$ apresentou, no total, 88\% de sucesso em promover anestesia pulpar durante a terapia endodôntica.

Bigby et al. (2006) deteminaram a eficácia anestésica e efeito na freqüência cardíaca de 1,8 ml de articaína 4\% com 1:100.000 de epinefrina em 37 dentes mandibulares posteriores com diagnóstico de pulpite irreversível e que após bloqueio padrão do NAl tiveram dor de moderada a severa no acesso endodôntico. O sistema Stabident ${ }^{\circledR}$ (Fairfax Dental Inc., Miami, FL) mais uma vez foi usado e o sucesso da injeção foi definido como dor ausente a leve durante o acesso endodôntico depois da injeção IO. O sucesso anestésico foi obtido em $86 \%$ dos casos (32 de 37) e a frequência cardíaca média aumentou 32 batimentos por minuto (bpm) durante a injeção IO.

Uma técnica bastante antiga que se tornou popular é a injeção do ligamento periodontal (PDL) ou intraligamentar. Originalmente conhecida como injeção peridental foi discutida nos compênios de anestesia local de 1912 a 1923 . No início de 1980, a injeção do ligamento periodontal ganhou popularidade, que mantêm até 
hoje, devido ao interesse dos fabricantes de dispositivos projetados para tornar a

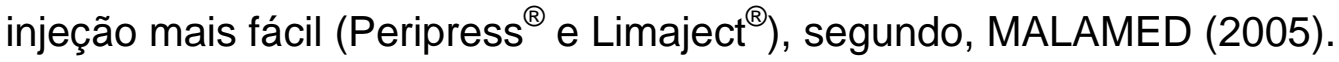

O mesmo autor salienta que, embora as seringas de injeção do ligamento periodontal "especiais" possam ser usadas com eficácia e segurança, elas geralmente não são necessárias e uma seringa de anestésico local convencional é igualmente eficaz na produção de anestesia do ligamento periodontal. As contraindicações da injeção do ligamento periodontal incluem infecção ou inflamação grave no local da injeção e dentes decíduos. O mecanismo pelo qual a solução anestésica chega aos tecidos periapicais é por difusão apical através de espaços medulares no osso intraseptal. A injeção do ligamento periodontal é segura para o tecido periodontal, além disso, não há evidências de que a inclusão do vasoconstritor na solução anestésica local possui qualquer efeito prejudicial na microcirculação pulpar.

Walton e Abbott (1981) afirmam que a injeção periodontal é a mais vantajosa entre as técnicas complementares, principalmente por não precisar de equipamento especial, a mesma agulha usada na injeção padrão pode ser utilizada, o lençol de borracha não precisa ser removido, a latência é muito rápida e o sucesso é, usualmente. Sá saliente que o fator mais crítico para sucesso é a pressão.

Os autores ainda afirmam que apesar de vários autores questionarem o prejuízo da injeção no ligamento periodontal ao periodonto, esta suposta destruição nunca foi demonstrada experimentalmente e em seus estudos os pacientes não relataram desconforto após o procedimento e nem mudanças visíveis nos tecidos, fato que também tem sido confirmado por estudos histológicos em macacos.

Pashley (1986) pesquisou os efeitos sistêmicos das injeções do ligamento periodontal em cães, usou uma seringa pistola para injetar $0,3 \mathrm{ml}$ de cada solução 
utilizada: solução salina; lidocaína 2\% com e sem 1:100.00 de epinefrina; mepivacaína 3\% e epinefrina na concentração de 1:100.000 sozinha. As vias de administração intravenosa, intraóssea, intrapulpar, subcutânea, periodontal intramuscular e submucosa foram usadas. A solução salina, a lidocaína $2 \%$ e mepivacaína 3\% não tiveram efeitos mensuráveis nos parâmetros sistêmicos independente do local da injeção. A lidocaína 2\% com epinefrina e a epinefrina sozinha causou diminuição transitória da pressão e aumento da freqüência cardíaca quando das injeções intravenosa, intraóssea e periodontal. Esses efeitos não foram detectados quando da injeção intramuscular, subcutânea, submucosa ou intrapulpar. Esses resultados suportam, segundo o autor, que a injeção periodontal é intraóssea por natureza e que as soluções injetadas pela técnica periodontal é rapidamente absorvida na circulação sistêmica. Porém, o mesmo defende o uso do vasoconstritor na injeção do ligamento periodontal, baseado no estudo de Kafman, LeResche e Sommers $^{8}$ (1984, apud PALASHED, 1986), em que concluíram que a duração da anestesia pulpar em humanos varia de 1 minuto a 27 minutos usando a lidocaína $2 \%$, respectivamente, sem e com epinefrina e, portanto, um vasoconstrictor é necessário nas injeções do ligamento periodontal para produzir anestesia local de duração suficiente para ser clinicamente aceitável. No entanto, Palashed (1986) recomendou injeção lenta, e quando do uso em mais de um dente, ou se os pacientes apresentarem doenças cardiovasculares severas ou arritmias cardíacas, devem receber infiltração ou injeção por bloqueio ao invés da injeção do ligamento periodontal.

Edwards e Head (1989) realizaram um teste clínico em 28 pacientes para investigar a efetividade da injeção primária do ligamento periodontal em promover

\footnotetext{
${ }^{8}$ Kaufman E, LeResche L, Sommers E. Intraligamentary anesthesia:a double-blind comparative study. J Am Dent Assoc 1984;108:175-8.
} 
anestesia para a realização de extração dental de rotina. As injeções foram administradas sob forte pressão utilizando uma seringa Ligmaject ${ }^{\circledR}$ (IMA Associates Us, Inc., CA) e um volume de 0,2 $\mathrm{ml}$ na superfície mesio vestibular, disto vestibular, mesio lingual e disto lingual, totalizando 0,8 $\mathrm{ml}$ em cada dente. As soluções empregadas foram: lidocaína 2\% em 14 dentes; epinefrina na concentração de 1:100.000 em 7 dentes e solução salina normal em 7 dentes. $O$ alcance da anestesia foi avaliado por resposta do dente a um "pulptester", sondagem gengival ao redor do dente e habilidade de extração sem dor. A injeção do ligamento periodontal com lidocaína foi estatisticamente e clinicamente mais efetiva na obtenção de anestesia e somente ela possibilitou a realização das extrações. Os autores concluíram que a pressão hidrostática não tem efeito direto na produção da anestesia do ligamento periodontal.

Segundo Schleder et al. (1988) a injeção do ligamento periodontal pode ser usada como uma técnica primária ou complementar. As taxas de sucesso quando usada como anestesia primária variam de $81 \%$ a $86 \%$ e quando usada como anestesia complementar variam de $83 \%$ a 92\%. Os autores avaliaram a eficácia anestésica primária da injeção do ligamento periodontal da lidocaína 2\%, mepivacaína 3\%, epinefrina na concentração de 1:100.000 sozinha e lidocaína 2\% com 1:100.000 de epinefrina, por meio do teste elétrico da polpa, em pré-molares inferiores. A solução de lidocaína 2\% com 1:100.000 de epinefrina anestesiou significativamente mais os primeiros pré-molares ( $87 \%$ de sucesso) com uma duração mais longa (20 minutos) do que as outras. A mepivacaína 3\% anestesiou 42\% dos dentes e teve uma duração de 4 minutos, a lidocaína 2\% anestesiou 14\% dos dentes e teve uma duração de 2 a 4 minutos, enquanto a epinefrina sozinha não anestesiou nenhum dente. O desconforto após as injeções foi reportado por 88\% 
dos pacientes por aproximadamente 2,4 dias e 50\% relataram sentir o dente mais alto em oclusão por um período comum de 2 dias. Nenhum dano pulpar ou periodontal foi observado clinicamente.

Childers et al. (1996) avaliaram a contribuição da injeção complementar do ligamento periodontal ao bloqueio do NAI em primeros molares humanos. Foi utilizado um "pulptester" (Analytic Technology Corp. ${ }^{\circledR}$, Redmond, WA) para medir a anestesia pulpar e uma escala de dor numérica verbal de 0 a 3 para avaliar 0 desconforto da injeção do ligamento periodontal e a seringa Limaject ${ }^{\circledR}$ para a injeção. A solução anestésica utilizada foi a lidocaína 2\% com 1:100.000 de epinefrina, a dose para o bloqueio do NAI foi de 1,8 $\mathrm{ml}$ e para a injeção do ligamento periodontal foi de 0,2 a $0,10 \mathrm{ml}$ na distal e mesial do dente. Cem por cento dos pacientes tiveram a anestesia do lábio com o bloqueio do NAI. Quando a combinação das injeções (bloqueio do NAI + injeção do ligamento periodontal) foi comparada com o bloqueio do NAI, a incidência do sucesso da anestesia pulpar (leitura 80) foi significantemente maior para a combinação das injeções durante os primeiros 23 minutos. Para a inserção da agulha na injeção do ligamento periodontal, a taxa do desconforto foi de nenhuma ou fraca em $98 \%$ e para a deposição da solução anestésica foi de 99\%.

A anestesia intraligamentar com vasoconstritor apresenta comprovadamente melhor eficácia do que sem a presença do vasoconstritor. Porém a administração de epinefrina pelo método intraligamentar deveria ser evitada em alguns pacientes com doença cardíaca severa. A ropivacaína, que é relativamente recente no arsenal de anestésicos locais, possui propriedades vasoconstritoras. Baseado nessas afirmações, Meechan (2002) investigou a eficácia anestésica de duas concentrações de ropivacaína $(0,75 \%$ e $1 \%)$ comparadas à lidocaína $2 \%$ com 1:80.000 de 
epinefrina na anestesia intraligamentar. Cada anestésico foi administrado em 32 dentes (16 incisivos superiores e 16 pré-molares inferiores), e um "pulptester" foi utilizado a cada minuto por 29 minutos após as injeções. O desconforto à injeção (medido através da escala visual analógica - VAS) e os efeitos adversos também foram registrados. A lidocaína com epinefrina obteve maior sucesso em obter anestesia pulpar do que as soluções de ropivacaína. O desconforto às injeções e os efeitos adversos foram similares entre as soluções e não produziram nenhum efeito adverso. O autor concluiu que a lidocaína com epinefrina é mais efetiva do que a ropivacaína como anestésico intraligamentar.

Berlin et al. (2005) realizaram um estudo prospectivo, aleatório e duplo-cego para comparar a eficácia anestésica da injeção intraligamentar de 1,4 ml das soluções de articaína 4\% e lidocaína 2\%, ambas associadas à epinefrina na concentração de 1:100.000. Utilizaram um sistema de deposição do anestéscico local computadorizado (Wand Plus ${ }^{\circledR}$ - Compudent; Milestone scientific, deerfield, III). As injeções intraligamentares foram realizadas na superfície mesial e distal do primeiro molar mandibular em 51 indivíduos, totalizando 102 injeções. Um "pulptester" foi usado a cada ciclo de 2 minutos por 60 minutos. A anestesia foi considerada bem sucedida quando duas leituras 80 negativas consecutivas (estímulo máximo) foram obtidas dentro de 20 minutos. A anestesia foi obtida em $86 \%$ dos primeiros molares com a solução de articaína e $74 \%$ com a solução de lidocaína, porém essa diferença não foi significante. A latência da anestesia pulpar para o primeiro molar foi de 1,3 minutos para a articaína e de 2,2 minutos para a lidocaína e essa diferença foi significante. Já a duração foi de 34 minutos e 31 minutos, respectivamente para a articaína e a lidocaína e a diferença não foi 
significante. No entanto, os autores concluíram que a eficácia anestésica da articaína foi similar à eficácia da lidocaína.

\subsection{Articaína}

O cloridrato de articaína foi descoberto em 1969. Originalmente conhecido como cloridrato de carticaína, a partir de 1976 passou a ser chamado de cloridrato de articaína. Possui propriedades similares à lidocaína, mas algumas propriedades adicionais a tornam atrativa para uso odontológico (MALAMED, 1992).

A articaína foi introduzida na Alemanha e na Suíça em 1976, na Holanda em 1978, na Áustria e na Espanha em 1980, no Canadá em 1983, no Brasil em 1999 e nos Estados Unidos em 2000 (MALAMED, 2005; MIKESELL et al., 2005). É o anestésico mais utilizado em vários países europeus (VANEEDEN; PATEL, 2002), inclusive na Alemanha (DAUBLANDER; MULLER; LIPP, 1997; JAKOBS et al., 1995), onde corresponde a $80 \%$ dos anestésicos locais vendidos para uso odontológico (MALAMED, 2000).

É também o anestésico local mais utilizado pelos dentistas no Canadá. Em estudo conduzido por Haas e Lennon (1995) em que foram determinados os anestésicos mais usados em Ontário, $23,4 \%$ de todas os tubetes utilizados eram de lidocaína com epinefrina 1:100.000, 19,9\% de articaína com epinefrina 1:200.000 e 17,9\% de articaína com epinefrina 1:100.000. Somando-se as duas últimas soluções tem-se que $37,8 \%$ dos tubetes anestésicos usados eram de articaína.

Como a articaína é uma droga relativamente nova nos Estados Unidos, tem sido sujeita a muita discussão entre os cirurgiões-dentistas que apontam algumas 
características boas (início de ação rápido e elevadas taxas de sucesso) e algumas ruins (risco aumentado de parestesia) (MALAMED, 2005).

A articaína difere dos demais anestésicos do tipo amida por duas características que lhe são peculiares: primeiro, o fato de possuir um anel tiofeno ao invés de um anel benzeno em sua porção lipofílica, o que seria responsável por conferir-Ihe maior lipossolubilidade em relação aos demais anestésicos (LEMAY et al., 1984; OERTEL; RAHN e KIRCH, 1997), e, segundo, por possuir uma cadeia radical éster, que permite sua biotransformação no plasma através da ação das plasma esterases, bem como no fígado, pelas enzimas microssomais hepáticas, isso provocaria uma hidrólise relativamente mais rápida, que ajudaria a diminuir a toxicidade associada à redução lenta da droga do local de injeção (YAGIELA, 1998).

O pH da articaína é de 4,4 a 5,2 para solução 1:100.000 e 4,6 a 5,4 para solução 1:200.000. A constante de dissociação $\left(\mathrm{pK}_{a}\right)$ da articaína é de 7,8 , sendo comparável à da lidocaína $(7,9)$. O valor do $\mathrm{pK}_{\mathrm{a}}$ está relacionado à velocidade do início de ação dos anestésicos locais, que para a articaína é favorável (LEMAY et al., 1984).

A dose máxima de articaína 4\% recomendada para adultos é de $7 \mathrm{mg} / \mathrm{Kg}$ de peso corporal. Sendo assim, em um indivíduo adulto com $70 \mathrm{Kg}$ de peso corporal poderá ser administrado até 7 tubetes contendo $1,8 \mathrm{ml}$ da solução de articaína cada um. (LEMAY et al., 1984).

No que diz respeito à segurança relacionada ao uso da articaína, Malamed, Gagnon e Leblanc (2001) relataram que a articaína foi bem tolerada em 882 pacientes que receberam a droga em estudos clínicos. Concluíram que a articaína 4\% com epinefrina 1:100.000 é segura para anestesia local em Odontologia, 
podendo ser usada tanto em adultos quanto em crianças. Sua toxicidade foi comparável à da lidocaína.

O potencial imunogênico da articaína é muito baixo e relatos de reações alérgicas são raros. No entanto, um antioxidante associado à articaína, o biossulfito de sódio, pode causar reações alérgicas. Outra contra-indicação é a alergia a drogas que contenham enxofre, já que este elemento faz parte da constituição do anel tiofeno presente na estrutura molecular da articaína. Reações alérgicas relatadas à articaína incluem edema, urticária, eritema e choque anafilático (MALAMED, 2005).

A articaína como a prilocaína tem um potencial para causar metahemoglobinemia e neuropatias. A metahemoglobinemia foi observada apenas após injeção intravenosa em anestesia regional e não em doses habituais usadas em Odontologia. Mesmo assim, a articaína está contra-indicada em pacientes com metemoglobinemia idiopática ou congênita, anemia ou insuficiência cardíaca ou respiratória evidenciada por hipóxia (MALAMED; GAGNON; LEBLANC, 2001)

Haas e Lennon (1995) investigaram a incidência de neuropatias induzidas por anestésicos locais. A incidência de neuropatias (com envolvimento do lábio e ou língua) associadas à articaína e à prilocaína foi aproximadamente cinco vezes à encontrada com lidocaína e mepivacaína. Entretanto, a incidência foi de somente 14 casos em 11 milhões de injeções, aproximadamente uma em 785.000 injeções. Portanto, embora a incidência de parestesia seja mais alta com articaína e prilocaína, ela ainda é um evento clínico raro.

Malamed, Gagnon e Leblanc (2001), num total de 1325 pacientes encontraram uma a incidência de parestesia de 1\% (8 casos) para o grupo de articaína, e 1\% (5 casos) para o grupo de lidocaína. Em todos os casos as parestesias foram solucionadas. 
Apesar dessas vantagens, a articaina não tem se mostrado estatisticamente superior à lidocaína na anestesia mandibular (MALAMED, GAGNOM e LEBLANC 2001; TÓFOLI et al., 2003; CLAFFEY et al., 2004; MIKESELL et al., 2005). Na anestesia infiltrativa na maxila têm-se encontrado efeito equivalente entre a articaína e lidocaína (VAHATALO, ANTILA e LEHTINEN, 1993; OLIVEIRA et al., 2004). Exceção se faz a dois recentes estudos; Kanaa et al. (2006) e Costa et al. (2005), respectivamente na mandíbula e maxila.

Kanaa et al. (2006) compararam a eficácia da infiltração vestibular da articaína 4\% e lidocaína 2\% (ambas com concentração de epinefrina 1:100.000) em promover anestesia pulpar do $1^{0}$ molar mandibular. Foi utilizado um estimulador pulpar elétrico (Analytic Technology ${ }^{\circledR}$, Redmond, WA) em intervalos de 2 minutos até 30 minutos após a injeção. As infiltrações com articaína obtiveram significativamente mais episódios de ausência de resposta à estimulação máxima do aparelho (64,5\%) do que as com lidocaína (38,7\%), e portanto, concluíram que a infiltração vestibular mandibular é mais efetiva com articaína $4 \%$ do que com lidocaína 2\%, ambas com a mesma concentração de epinefrina.

Costa et al. (2005) realizaram estudo para comparar a latência e duração pulpar, utilizando um verificador elétrico da polpa (Vitality Scanner Model $2005^{\circledR}$ Analytic Endodontics) em 20 pacientes que receberam aleatoriamente três soluções anestésicas locais: lidocaína 2\% associada à epinefrina 1:100.000, articaína 4\% associada à epinefrina 1:100.000 e articaína 4\% associada à epinefrina 1:200.000, na anestesia infiltrativa do maxilar superior para realização de procedimento restaurador de baixa complexidade. Os valores da latência foram, respectivamente, de 2,8, 1,4 e 1,6 minutos, e da duração foram 39,2, 66,3 e 56,7 minutos. As 
diferenças entre as soluções de lidocaína e as duas soluções de articaína foram significantes, porém para as soluções de articaína entre si, não foram significantes. 


\section{PROPOSIÇÃO}

3.1 Comparar a eficácia anestésica (variáveis: sinal subjetivo de anestesia do lábio; presença de anestesia pulpar; ausência de dor durante o procedimento de pulpectomia) da articaína 4\% com a lidocaína 2\%, ambas associadas à epinefrina 1:100.000, no bloqueio convencional do nervo alveolar inferior em dentes posteriores mandibulares com diagnóstico de pulpite irreversível.

3.2 Comparar a eficácia anestésica (variáveis: presença de anestesia pulpar e ausência de dor durante o procedimento de pulpectomia) da articaína 4\% com a lidocaína 2\%, ambas associadas à epinefrina 1:100.000, na injeção no ligamento periodontal (anestesia complementar) em dentes posteriores mandibulares com diagnóstico de pulpite irreversível. 


\section{MATERIAL E MÉTODO}

\subsection{Material}

\subsubsection{Material humano}

\section{Seleção de pacientes:}

Foram selecionados 40 pacientes do Setor de Urgência com pulpite irreversível, que possuem as seguintes características:

- Saudáveis conforme determinou o questionário de histórico de saúde (anamnese) com confirmação verbal ;

- Normorreativos, com pressão arterial sistólica abaixo de 140 mmHg e diastólica abaixo de $90 \mathrm{mmHg}$;

- Freqüência cardíaca entre 70-/+ 20 batimentos /minuto;

- idade entre 18 a 50 anos de idade

- Que apresentassem necessidade de pulpectomia em pelo menos um dente mandibular posterior

- Que apresentassem pelo menos um dente adjacente e um canino contralateral hígidos ou sem presença de cáries profundas, restaurações extensas, doença periodontal avançada e sem história de trauma ou sensibilidade

\section{Foram excluídos do estudo}


- Pacientes com histórico de sensibilidade aos anestésicos locais e/ou ao enxofre;

- Grávidas ou com suspeita de gravidez;

- Aqueles que estavam tomando medicações que pudessem interagir com o anestésico local, tais como, ansiolíticos, antidepressivos, antipsicóticos e agentes anti-histamínicos;

- Pacientes com processo séptico próximo ao local da injeção;

- Os que estivessem sob tratamento ortodôntico;

- Portadores de cardiopatias, doença neurológica, hipertiroidismo e diabetes.

\section{Sobre os dentes que foram realizados a pulpectomia}

- Dentes mandibulares posteriores com diagnóstico de pulpite irreversível, ou seja, com dor expontânea de moderada a severa e com resposta positiva ao teste elétrico da polpa e uma resposta prolongada à prova de gelo (Endo-Frost Contene - Roeko ${ }^{\circledR}$, Germany).

\section{Sobre os dentes que foram submetidos ao teste elétrico}

- O dente mandibular posterior com diagnóstico de pulpite irreversível, um dente adjacente e o canino contralateral hígidos ou sem presença de cáries profundas, restaurações extensas, doença periodontal avançada e sem história de trauma ou sensibilidade. Os dentes foram isolados com roletes de algodão, secos com jatos de ar e aplicado o gel condutor de eletrocardiograma e ultrassonografia ao nível médio da coroa para estabelecer contato entre o dente e a ponta ativa do aparelho.

\subsubsection{Material permanente}




\section{Infraestrutura}

- Consultórios localizados no Setor de Urgência da Faculdade de Odontologia da Universidade de São Paulo.

\section{Equipamento para a realização dos testes elétricos da polpa dos respectivos} dentes

- Aparelho estimulador pulpar elétrico Vitality Scanner $2006^{\circledR}$, SybronEndo, CA, USA (Figura 1)

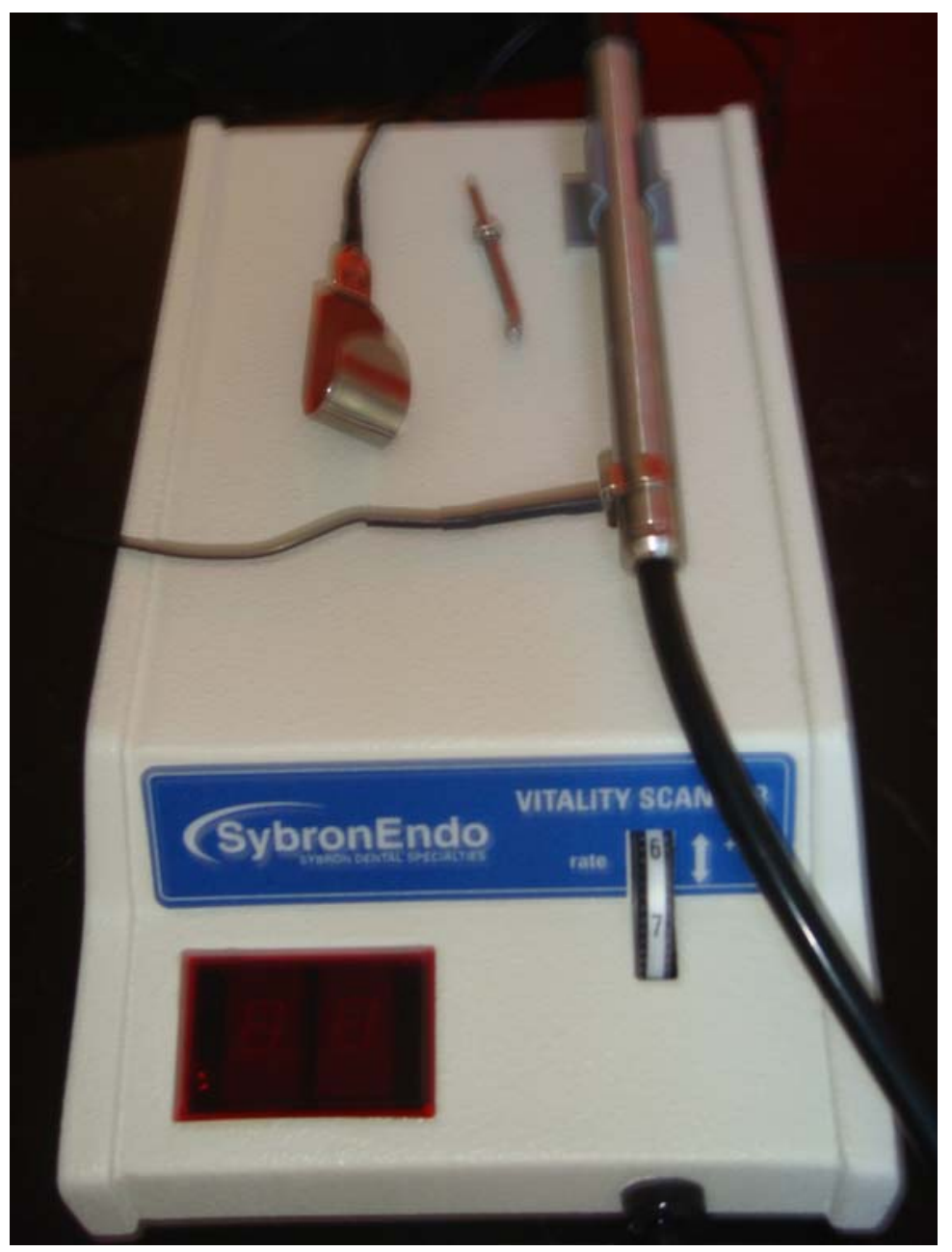

Figura 4.1 - Aparelho estimulador pulpar elétrico Vitality Scanner $2006^{\circledR}$, SybronEndo, CA, USA 
Instrumental para exame clínico

- Espelho clínico, explorador duplo de ponta ativa reta, pinça clínica

\section{Instrumental para anestesia local}

\section{Bloqueio do nervo alveolar inferior}

- Seringa carpule com carga lateral e dispositivo para aspiração com argola Konenn ${ }^{\circledR}$ (Kennen Indústria e Comércio Ltda, Brasil)

\section{Anestesia do ligamento periodontal}

- Seringa carpule com retrocarga Health $\mathrm{Co}^{\circledR}$, USA

\section{Instrumental para realização da pulpectomia}

- Instrumentos rotatórios com irrigação (alta rotação), ponta diamantada esférica da KG Sorensen ${ }^{\circledR} 1019$ ou $1016 \mathrm{HL}$, limas de endodontia tipo Kerr e/ou tipo Hedstroem, espátula para inserção do material restaurador provisório, cânula de endodontia para aspiração, seringa luer para irrigação, curetas de dentina.

\subsection{Material de consumo}

\section{Para o procedimento de pulpectomia}

- Algodão, cimento de óxido de zinco e eugenol, hipoclorito de sódio a 0,5\% (líquido de Dakin), medicação intracanal PRP (paramonoclorofenol 2\%, rinosoropolietilenoglicol 400-qsp 98\% - Fórmula e Ação ${ }^{\circledR}$ )

\section{Para anestesia local}


- Agulha longa de calibre 27 e agulha curta de calibre 30 (Teruno Dental Needle ${ }^{\circledR}$ DFL, Indústria e comércio Ltda)

- Cloridrato de articaína 4\% associado a epinefrina 1:100.000 (Lidocaína 100 ${ }^{\circledR}$ DFL , Indústria e comércio Ltda)

Cada 1,8 ml da solução contém: $72 \mathrm{mg}$ de cloridrato de articaína; $18 \mu \mathrm{g}$ de epinefrina; 1,8 ml de excipiente q.s.p; excipientes: metabissulfito de sódio, cloreto de sódio e água para injeção

- Cloridrato de lidocaína 2\% associado a epinefrina 1:100.000 (Articaine100 ${ }^{\circledR}$ - DFL, Indústria e comércio Ltda)

Cada 1,8 ml da solução contém: 36 mg de cloridrato de lidocaína; $18 \mu \mathrm{g}$ de epinefrina; 1,8 ml de excipiente q.s.p; excipientes: bissulfito de sódio, cloreto de sódio e água para injeção

- Gel tópico - Benzocaína ${ }^{\circledR}$ 200mg/g-20\% (DFL, Indústria e comércio Ltda)

Para estabelecer condução eletrônica entre o dente e a polpa do "pulptest" testador pulpar elétrico

- Gel condutor de eletrocardiograma e ultrassonografia (MedSystem ${ }^{\circledR}$ )

Para a realização do teste de vitalidade pulpar com a finalidade do diagnóstico de pulpite irreversível

- Endo-Frost - 200ml ( $-50^{\circ} \mathrm{C}$ ) (Contene-Roeko ${ }^{\circledR}$ - Germany

\section{Para exame radiográfico quando necessário}

- Filme radiográfico (periapical), tipo Ektaspeed $\left(\operatorname{Kodak}^{\circledR}\right)$ 


\subsection{Métodos}

A amostragem foi dividida em dois grupos e dois subgrupos de acordo com o anestésico local e a técnica anestésica empregada. A existência dos subgrupos está na dependência do insucesso do primeiro grupo, ou seja, da primeira técnica anestésica empregada:

\section{Grupo A}

A1 - Injeção do bloqueio do nervo alveolar inferior com cloridrato de articaína 4\% com epinefrina 1:100.000 $(n=20)$

\section{Subgrupo A}

A2 - Injeção no ligamento periodontal com cloridrato de articaína 4\% com epinefrina 1:100.000 + injeção do bloqueio do nervo alveolar inferior realizada anteriormente

\section{Grupo B}

B1 - Injeção do bloqueio do nervo alveolar inferior com cloridrato de lidocaína 2\% com epinefrina 1:100.000 $(n=20)$

\section{Subgrupo B}

B2 - Injeção no ligamento periodontal com cloridrato de lidocaína 2\% com epinefrina 1:100.000 + injeção do bloqueio do nervo alveolar inferior realizada anteriormente

\subsubsection{Variáveis estudadas}


- sinal subjetivo de anestesia do lábio, presença da anestesia pulpar e ausência de dor durante o procedimento de pulpectomia após bloqueio convencional do nervo alveolar inferior.

- presença da anestesia pulpar e ausência de dor durante o procedimento de pulpectomia após injeção complementar no ligamento periodontal .

\subsection{Obtenção e registro dos testes de vitalidade pulpar}

Os testes de vitalidade pulpar foram realizados no dente portador de pulpite irreversível, no dente adjacente e no contralateral através do estimulador pulpar elétrico (Vitality Scanner $2006^{\circledR}$, SybronEndo, CA, USA). O monitor de vitalidade pulpar se liga automaticamente assim que for estabelecido contato entre o dente e a ponta da sonda. Para facilitar a condução eletrônica foi aplicado gel condutor utilizado em eletrocardiografia e ultrassonografia (MedSystem ${ }^{\circledR}$ ) entre a parte média do dente e a ponta da sonda. A percepção do estímulo se manifesta por uma pressão pulsátil, morna ou formigante. A velocidade de corrente é estabelecida em 25 segundos para aumentar desde a potência nula (0) até a potência máxima (80). A luz indicadora da sonda alerta quando alcançada a potência máxima. O critério para anestesia pulpar bem sucedida foi a resposta negativa ao estímulo máximo da polpa (80) realizado por um "pulptester" por duas vezes consecutivas. Os testes elétricos de vitalidade pulpar foram realizados sempre nos seguintes períodos:

- imediatamente antes da primeira anestesia do bloqueio convencional do nervo alveolar inferior para se obter os valores médios de base de cada dente. 
- 10 minutos após bloqueio convencional do nervo alveolar inferior (momento em que foi questionado sobre a anestesia do lábio) ou seja; imediatamente antes do início dos procedimentos de pulpectomia.

- imediatamente depois de concluída a anestesia complementar no ligamento periodontal, caso essa fosse necessária.

3.2.3 Obtenção e registro da anestesia do lábio subjetiva

A presença da anestesia do lábio foi monitorada fazendo-se a pergunta: "Seu lábio está anestesiado?" ou "Seu lábio está entorpecido?"

Essa indagação foi realizada após 10 minutos do final das duas injeções consecutivas de soluções anestésicas pela técnica do bloqueio convencional do NAI, momento em que, logo após, se deu início aos procedimentos de pulpectomia.

3.2.4 Obtenção e registro da dor durante o procedimento de pulpectomia

Foi utilizada uma escala numérica verbal de 0 a 3 para registrar a intensidade da dor relatada e a proporção do acesso alcançado (dentina, entrada da câmara pulpar ou no canal) quando o paciente sentiu dor.

Escala numérica para avaliação da dor:

\begin{tabular}{|c|c|c|c|}
\hline $\mathbf{0}$ & $\mathbf{1}$ & $\mathbf{2}$ & $\mathbf{3}$ \\
\hline $\begin{array}{c}\text { Ausência } \\
\text { de dor }\end{array}$ & $\begin{array}{c}\text { Dor fraca / } \\
\text { não desconfortável }\end{array}$ & $\begin{array}{c}\text { Moderada/ } \\
\text { desconfortável }\end{array}$ & $\begin{array}{c}\text { severa /Intensa } \\
\text { intolerável }\end{array}$
\end{tabular}




\subsubsection{Dinâmica da experiência}

No paciente que procurou o Setor de Urgência da Faculdade de Odontologia da Universidade de São Paulo por motivo de dor de dente, foi realizada a anamnese com detalhes sobre sua historia médica e dental.

Após a conclusão do diagnóstico clínico de pulpite irreversível, ou seja; presença de dor expontânea de moderada a severa e uma resposta prolongada à prova de gelo (Endo-Frost ${ }^{\circledR}$ ) em um dente posterior da mandibula, que tenha um dente adjacente e um canino contralateral hígidos ou sem presença de cáries profundas, restaurações extensas, doença periodontal avançada e sem história de trauma ou sensibilidade, foi questionada a participação e colaboração expontânea com essa pesquisa clínica. O termo de consentimento livre e esclarecido foi assinado pelo paciente, deixando claro que sua participação era voluntária.

Os testes de vitalidade pulpar foram realizados por 2 vezes consecutivas no dente com pulpite irreversível, no seu adjacente e no canino contralateral antes da administração da anestesia para se obter os valores médios de base.

Após a aplicação por 60 segundos de anestésico local tópico na região retromolar, dois tubetes anestésicos locais da mesma solução foram injetados $(3,6 \mathrm{ml})$, um em seguida ao outro, para o bloqueio convencional (padrão) do nervo alveolar inferior. A escolha da solução anestésica foi de modo aleatório. O tempo médio de injeção para cada tubete foi de aproximadamente 2 minutos.

Duas injeções foram administradas na tentativa de compensar a baixa freqüência documentada na literatura, e baseada na experiência clínica do Setor de 
Urgência da FOUSP, de se conseguir completa anestesia pulpar para dentes posteriores mandibulares com pulpite irreversível.

Após 10 minutos das injeções, os pacientes foram questionados sobre a anestesia profunda do lábio. À seguir foram realizados os testes elétricos de vitalidade pulpar por duas vezes consecutivas nos três dentes mencionados anteriormente. O canino contralateral não anestesiado foi usado como controle apenas para assegurar que o "pulptest" (verificador elétrico da polpa) estava operando corretamente e os pacientes estavam respondendo adequadamente. Duas respostas negativas dos pacientes à potência máxima do "pulptest" (80) foram usadas como critério para anestesia pulpar.

Os procedimentos da pesquisa tiveram continuidade com as manobras para o acesso da câmara pulpar.

Os pacientes foram instruídos a relatar qualquer desconforto durante o procedimento de abertura do dente, pois sendo assim o tratamento foi imediatamente interrompido. A intensidade de seu desconforto foi relatada usando uma escala numérica verbal de 0 a 3, onde zero é nenhuma dor, 1 dor fraca, suave (é sentida, mas não desconfortável), 2 dor moderada (desconfortável, mas não insuportável) e 3 severa (desconforto considerável e difícil de tolerar).

A proporção do acesso alcançado quando o paciente sentiu dor foi anotado como dentro da dentina, na câmara pulpar, ou no canal.

Nos pacientes que sentiram dor foram realizadas injeções complementares no ligamento periodontal (intraligamentar-PDL). As injeções foram administradas no sulco gengival por vestibular; na mesial (ângulo mesio-vestibular) e na distal (ângulo disto-vestibular), e por lingual; (ângulo mesio-lingual e ângulo disto-lingual) do dente portador de pulpite. Para os molares foram realizadas injeções no sulco gengival na 
região da furca por vestibular e por lingual. A quantidade total de solução injetada foi de $1,8 \mathrm{ml}$ para a superfície vestibular e 1,8 $\mathrm{ml}$ para a superfície lingual (aproximadamente 0,6 $\mathrm{ml}$ para cada injeção) totalizando 3,6 ml. A agulha foi inserida no sulco gengival entre o dente e a crista óssea em um ângulo de $30^{\circ}$ em relação ao longo eixo do dente e com o bisel voltado para o osso alveolar. A agulha foi introduzida com pressão firme até que não entrasse mais, para então ser depositada a solução anestésica sob pressão.

Imediatamente após a realização da anestesia no ligamento periodontal, os testes elétricos de vitalidade pulpar foram, novamente, realizados. Se a dor durante o procedimento de pulpectomia persistisse após as injeções complementares foi utilizada a injeção intrapulpar para possibilitar a conclusão da pulpectomia..

O sucesso do bloqueio do nervo alveolar inferior foi definido como a capacidade de acessar a câmara pulpar e realizar a pulpectomia sem que a dor relatada pelo paciente (escala 0 a 1 ) impedisse o prosseguimento do procedimento. O sucesso da anestesia complementar no ligamento periodontal foi definido se a pulpectomia foi completada sem dor (escala de 0 a 1).

As duas anestesias consecutivas do bloqueio convencional do NAI assim como as anestesias complementares foram realizadas pela pesquisadora principal. Os testes elétricos para verificação da anestesia pulpar foram realizados por um aluno da pós-graduação em ciências odontológicas - área de concentração em Clínica Integrada que não conhecia a identidade da solução anestésica utilizada.

\section{Fases da pesquisa}

\section{Fase pré-clínica}


Quatro tubetes sempre da mesma solução (dois para o bloqueio do nervo alveolar inferior e dois para a injeção no ligamento periodontal, caso fosse necessária) foram colocados em envelopes (um envelope para cada paciente) pela pesquisadora principal da pesquisa. A escolha do envelope foi aleatória para o uso nos pacientes.

\section{Fase de diagnóstico}

Esta fase compreendeu a anamnese, o exame clínico, assinatura do consentimento livre e esclarecido e a obtenção dos valores de base dos testes elétricos de vitalidade pulpar dos 3 dentes (portador de pulpite irreversível, o dente adjacente e o canino contralateral). Nessa fase também foi apresentada a escala de dor numérica verbal de 0 a 3 para que os pacientes se familiarizassem com a nomenclatura.

\section{Fase anestésica 1}

Compreenderá a aplicação tópica do anestésico local (Benzocaína 20\%), as duas injeções consecutivas do bloqueio do nervo alveolar inferior, os 10 minutos após a injeção para completar a anestesia do lábio, os testes elétricos de vitalidade pulpar para a verificação da anestesia pulpar e o procedimento de pulpectomia. Caso o paciente relatasse algum desconforto de dor superior a 1 durante 0 procedimento de pulpectomia, a proporção do acesso alcançado foi anotado e o procedimento de pulpectomia foi interronpido e deu-se início à: 


\section{Fase anestésica 2}

Esta fase se iniciou com as injeções do ligamento periodontal, as quais foram administradas no ângulo mesio-vestibular, disto-vestibular, mesio-lingual e distolingual. Em se tratando de molares também foram realizadas injeções na região da furca por vestibular e por lingual. Foi administrado no total um volume de $3,6 \mathrm{ml}(1,8$ $\mathrm{ml}$ na superfície vestibular e 1,8 $\mathrm{ml}$ na lingual ). Os testes elétricos de vitalidade pulpar foram novamente realizados após as injeções do ligamento periodontal e a pulpectomia foi completada. Caso a injeção do ligamento periodontal não fosse efetiva o suficiente para que o procedimento de pulpectomia fosse completado, foi utilizada a anestesia intrapulpar.

\section{Fase da anestesia intrapulpar}

O objetivo desse estudo não foi avaliar a anestesia intrapulpar. Ela somente foi utilizada para que se pudesse concluir o procedimento de pulpectomia.

\subsubsection{Técnicas anestésicas}

\section{Técnica convencional (padrão) do bloqueio do nervo alveolar inferior}

A técnica padrão foi à utilizada no Setor de Urgência da FOUSP e baseada em Gregori e Santos (1996). Utilizando seringa carpule com dispositivo de aspiração e agulhas descartáveis de calibre 27, foram realizados testes de aspiração sanguínea ao início da anestesia, bem como na mudança de posição da agulha. A agulha deverá ser introduzida de 3 a $5 \mathrm{~mm}$, quando então se deposita uma 
quantidade aproximada de 0,3 $\mathrm{ml}$ da solução anestésica . Num segundo passo, a seringa deve ser levada até a região de pré-molares do lado oposto, e a agulha inserida até o contato ósseo; logo recua-se de 1 a $2 \mathrm{~mm}$ e injeta-se lentamente o restante de anestésico. O tempo de injeção total de cada anestesia deve ser de aproximadamente 2,0 minutos.

\section{Técnica do ligamento periodontal (complementar)}

Foram utilizadas uma seringa carpule normal e agulhas descartáveis de calibre 30. As injeções foram administradas no dente portador de pulpite irreversível, no sulco gengival e na superfície vestibular; ângulo mesio-vestibular e ângulo distovestibular; e na superfície lingual; ângulo mesio-lingual e ângulo disto-lingual. Para os molares também foram realizadas injeções no sulco gengival na região da furca por vestibular e por lingual. A quantidade total de solução injetada foi de 1,8 $\mathrm{ml}$ para a superfície vestibular e 1,8 $\mathrm{ml}$ para a superfície lingual (aproximadamente 0,6 ml para cada injeção). A agulha foi inserida no sulco gengival entre o dente e a crista óssea em um ângulo de $30^{\circ}$ em relação ao longo eixo do dente e com o bisel voltado para o osso alveolar. A agulha foi introduzida com pressão firme até que não entrasse mais, para então ser depositada a solução anestésica sob pressão. Essa técnica foi baseada em Gregori e Santos (1996).

\subsubsection{Técnica para a realização da pulpectomia}

A técnica utilizada foi a preconizada pelo Setor de Urgência da FOUSP e baseada em Alvares e Álvares (1994). A abertura coronária foi realizada com instrumentos de alta rotação e brocas esféricas diamantadas de pescoço longo da 
KG Sorensen de número 1019 HL. Ao acessar a câmara pulpar foi realizada a irrigação e aspiração com solução de hipoclorito de sódio a 0,5\% (líquido de Dakin). Com a penetração da ponta ativa da broca nos cornos pulpares, foi removido todo o resto do teto da câmara pulpar. A remoção da polpa coronária foi realizada com curetas de dentina ou com a própria broca e em seguida foi realizada novamente a irrigação-aspiração.

Os canais foram localizados e limas endodônticas do tipo Kerr (\# 8 a 20) e de preferência com $21 \mathrm{~mm}$ de comprimento, dependendo do diâmetro e comprimento médio dos canais, foram introduzidas na entrada dos canais. A penetração em direção ao ápice foi de forma lenta e gradativa, com o cuidado de sempre ficar aquém do comprimento médio dos dentes. A remoção da polpa foi então realizada com movimentos no sentido horário e o número de voltas necessárias para que ocorresse o enovelamento do tecido pulpar, o que geralmente é conseguido com uma a duas voltas completas. Removeu-se a lima do canal e, na maioria das vezes, esta trouxe a polpa ou fragmentos dela.

Cautela foi tomada nos canais mesiais de molares inferiores, pois ao girar a lima, esta corre o risco de fraturar, então pressão da lima contra as paredes do canal pôde trazer a polpa ou fragmentos dela. Para o canal distal dos molares inferiores foi necessário o uso de limas de maior calibre ou até uma lima do tipo Hedstroem modificada. No entanto, como a instrumentação completa dos canais não foi realizada naquele momento, a instrumentação não foi exagerada para não criar degraus, dificultando o tratamento posterior do tratamento endodôntico. Portanto, a finalidade do tratamento de urgência foi de somente realizar a pulpectomia com a finalidade de alívio da dor sem causar iatrogenia. 


\subsubsection{Método estatístico}

Foram construídas tabelas com os valores observados das estatísticas descritivas: média, desvio padrão, mínimo, mediana e máximo da idade dos pacientes para os dois grupos.

A dor foi categorizada de seguinte forma: escores 0 ou 1 formaram a categoria "sem dor", e escores 2 ou 3, a categoria "com dor".

Foram construídos gráficos de barras representando as porcentagens de ocorrências das categorias das respostas ao estímulo elétrico provocado pelo "pulptest" (negativa ou positiva) e da dor (com ou sem dor) nos dois grupos.

$\mathrm{Na}$ comparação dos dois grupos quanto às distribuições das respostas ao "pulptest" e dor foi feita por meio do teste Qui-quadrado, sendo utilizado o teste exato de Fisher quando o teste Qui-quadrado se mostrou inadequado (ocorrência de freqüências esperadas menores do que 5).

O teste de Kruskal - Wallis foi adotado na comparação das idades dos dois grupos. Foi adotado nível de significância de 0,05 em todos os testes de hipótese realizados

Toda a metodologia estatística utilizada pode ser encontrada em Fisher e Van Belle (1993). 


\section{RESULTADOS}

O gênero, a idade, o tipo do dente posterior e todos os dados coletados referentes às variáveis estudadas para cada paciente foram inseridos em uma planilha do programa Microsoft Excel ${ }^{\circledR}$, com a finalidade de se realizarem as análises estatísticas. Esses dados estão nos Apêndices A e B, respectivamente para as soluções de articaína e lidocaína.

\subsection{Gênero}

A porcentagem do gênero feminino para o grupo da articaína foi 50\% e para o grupo da lidocaína foi $70 \%$. Não foi detectada diferença significante entre as distribuições dos gêneros nos dois grupos $(p=0,197)$.

\subsection{Idade}

Na Tabela 5.1 estão apresentados os valores de estatísticas descritivas para a Idade nos dois grupos. As médias das idades dos dois grupos são próximas, o mesmo ocorrendo com as medianas. Não foi detectada diferença entre as distribuições das idades nos dois grupos $(p=0,432)$

Tabela 5.1 - Estatísticas descritivas para idade nos grupos articaína e lidocaína

\begin{tabular}{c|c|c|c|c|c|c}
\hline Grupo & N & Média & Desvio padrão & Mínimo & Mediana & Máximo \\
\hline Articaína & 20 & 29,9 & 9,8 & 18 & 29,5 & 53 \\
Lidocaína & 20 & 34,1 & 14,3 & 18 & 30,5 & 69 \\
\hline
\end{tabular}




\subsection{Tipo do dente posterior}

A Tabela 5.2. mostra as distribuições de freqüências e porcentagens dos dentes em cada grupo e total. Não foi detectada diferença significante entre as distribuições nos dois grupos $(p=0,411)$.

Tabela 5.2 - Distribuições das freqüências e porcentagens dos dentes em cada grupo e total

\begin{tabular}{c|c|c|c|c|c}
\hline & \multicolumn{4}{|c|}{ Dente } & \\
\hline Grupo & $\mathbf{1}^{\mathbf{0}}$ molar & $\mathbf{2}^{\mathbf{0}}$ molar & $\mathbf{2}^{\mathbf{0}}$ pré & $\mathbf{3}^{\mathbf{0}}$ molar & Total \\
\hline Articaína & 10 & 8 & 1 & 1 & 20 \\
& $50 \%$ & $40 \%$ & $5 \%$ & $5 \%$ & $100 \%$ \\
Lidocaína & 9 & 5 & 4 & 2 & 20 \\
& $45 \%$ & $25 \%$ & $20 \%$ & $10 \%$ & $100 \%$ \\
\hline Total & 19 & 13 & 5 & 3 & 40 \\
& $47,5 \%$ & $32,5 \%$ & $12,5 \%$ & $7,5 \%$ & $100 \%$ \\
\hline
\end{tabular}

\section{4 Sinal subjetivo da anestesia do lábio}

No tempo avaliado, ou seja, 10 minutos após o bloqueio convencional do NAI, o sinal subjetivo de anestesia do lábio foi relatado estar presente em todos os pacientes (100\%) em ambos os grupos. 


\subsection{Categorias das repostas ao "pulptest" após o bloqueio convencional do} NAI

A Tabela 5.3 e a Figura 5.1 apresentam as porcentagens de ocorrência de cada categoria da resposta ao "pulptest" (negativa ou positiva) nos dois grupos. Pelo teste Qui-quadrado, não foi detectada diferença significante entre as distribuições das categorias das respostas ao "pulptest" nos dois grupos $(p=0,736$

Tabela 5.3-Distribuições de freqüências e porcentagens das categorias das respostas ao "pulptest" nos dois grupos após bloqueio do NAI

\begin{tabular}{c|cc|c}
\hline \multirow{2}{*}{ Grupo } & \multicolumn{2}{|c|}{ Resposta "pulptest" } & \multirow{2}{*}{ Total } \\
\cline { 2 - 3 } & Negativa & Positiva & 20 \\
Articaína & 13 & 7 & $100 \%$ \\
& $65 \%$ & $35 \%$ & 20 \\
Lidocaína & 14 & 6 & $100 \%$ \\
& $70 \%$ & $30 \%$ & 40 \\
Total & 27 & 13 & $100 \%$ \\
\hline
\end{tabular}

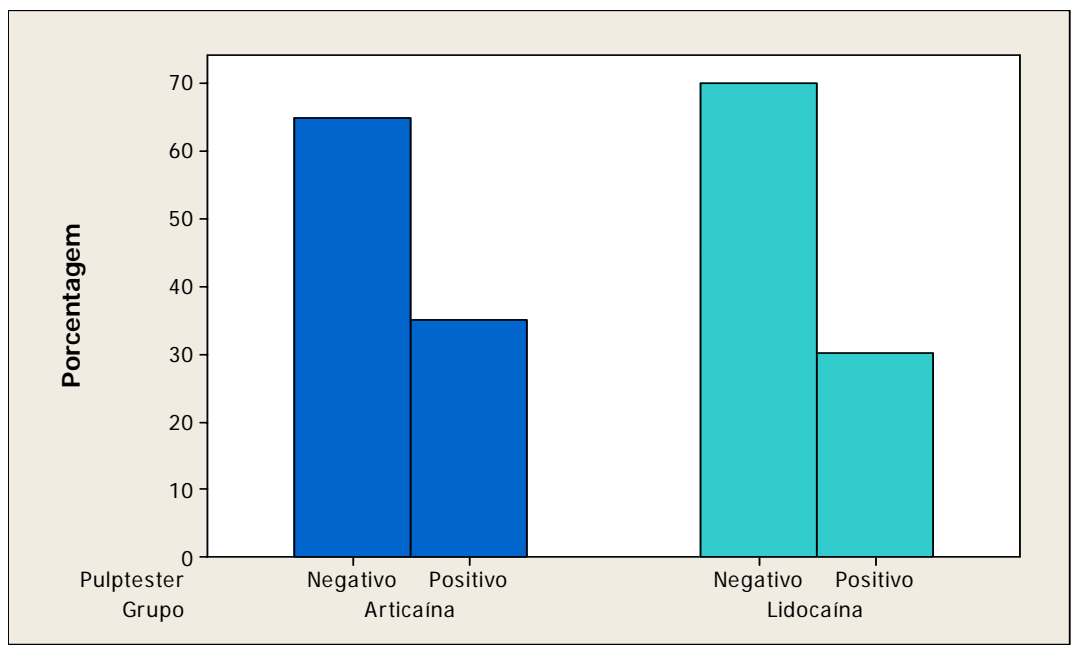

Figura 5.1 -Gráfico de barras das porcentagens de ocorrências das categorias das respostas ao "pulptest" nos grupos articaína e lidocaína - após bloqueio do NAI 


\subsection{Categorias da dor durante o procedimento de pulpectomia após o bloqueio do NAI}

As porcentagens de ocorrência ou não de dor (com ou sem dor) em cada grupo após o bloqueio convencional do NAl estão apresentadas na Tabela 5.4 e representadas na Figura 5.2.

Pelo teste Qui-quadrado, não foi detectada diferença significante entre as probabilidades de ocorrência de dor com os dois anestésicos $(p=0,204)$.

Tabela 5.4 - Distribuições de freqüências e porcentagens da dor nos dois grupos - após bloqueio do NAI

\begin{tabular}{c|c|c|c}
\hline & \multicolumn{2}{|c|}{ Dor } & \\
\hline Grupo & Com & Sem & Total_ \\
\hline Articaína & 7 & 13 & 20 \\
& $35 \%$ & $65 \%$ & $100 \%$ \\
Lidocaína & 11 & 9 & 20 \\
& $55 \%$ & $45 \%$ & $100 \%$ \\
\hline Total & 18 & 22 & 40 \\
& $45 \%$ & $55 \%$ & $100 \%$ \\
\hline
\end{tabular}

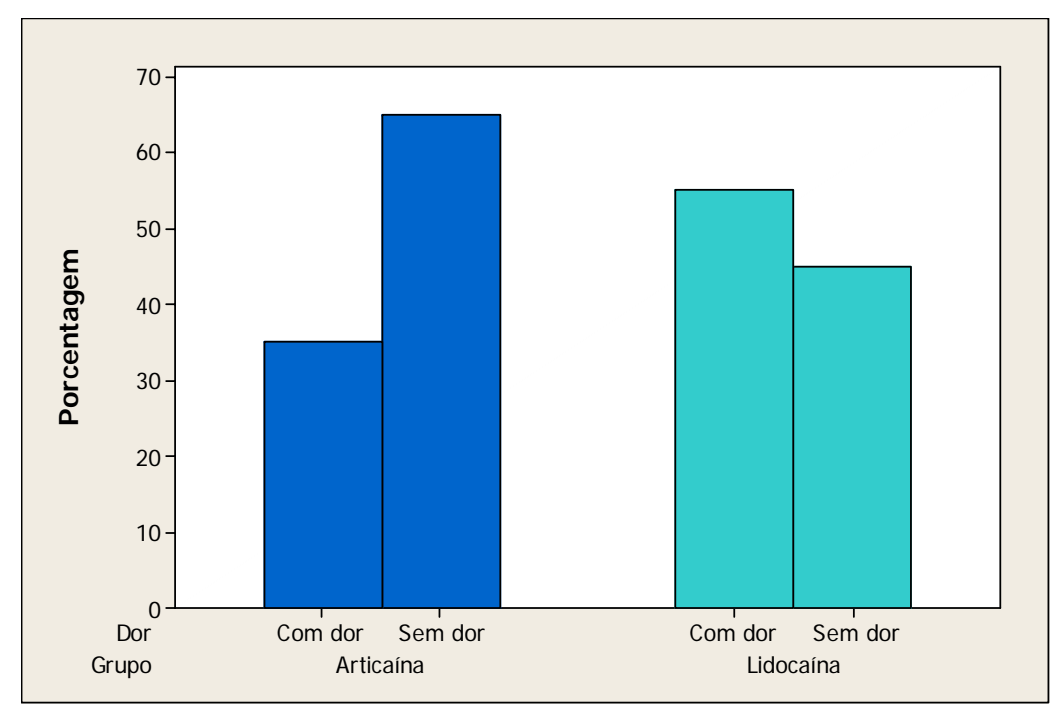

Figura 5.2 - Gráfico de barras das porcentagens de ocorrências das categorias da dor nos grupos articaína e lidocaínaapós bloqueio do NAl 


\subsection{Local onde a dor foi relatada após o bloqueio convencional do NAI}

Na Tabela 5.5 têm-se as freqüências e porcentagens dos locais em que os pacientes relataram dor após o bloqueio do NAI (18 pacientes) nos dois grupos. As porcentagens de ocorrências de dor em cada local estão representadas na Figura 5.3

Tabela 5.5 - Distribuições de freqüências e porcentagens dos locais onde a dor foi relatada nos dois grupos após bloqueio do NAI

\begin{tabular}{c|c|c|c|c}
\hline \multirow{2}{*}{} & \multicolumn{3}{|c|}{ Local } & \\
\cline { 2 - 5 } & câmara & canal & dentina & Total \\
\hline Articaína & 5 & 0 & 2 & 7 \\
\hline & $71,4 \%$ & $0 \%$ & $28,6 \%$ & $100 \%$ \\
\hline Lidocaína & 5 & 2 & 4 & 11 \\
\hline & $45,5 \%$ & $18,2 \%$ & $36,4 \%$ & $100 \%$ \\
\hline Total & 10 & 2 & 6 & 18 \\
\hline & $55,6 \%$ & $11,1 \%$ & $33,3 \%$ & $100 \%$ \\
\hline
\end{tabular}

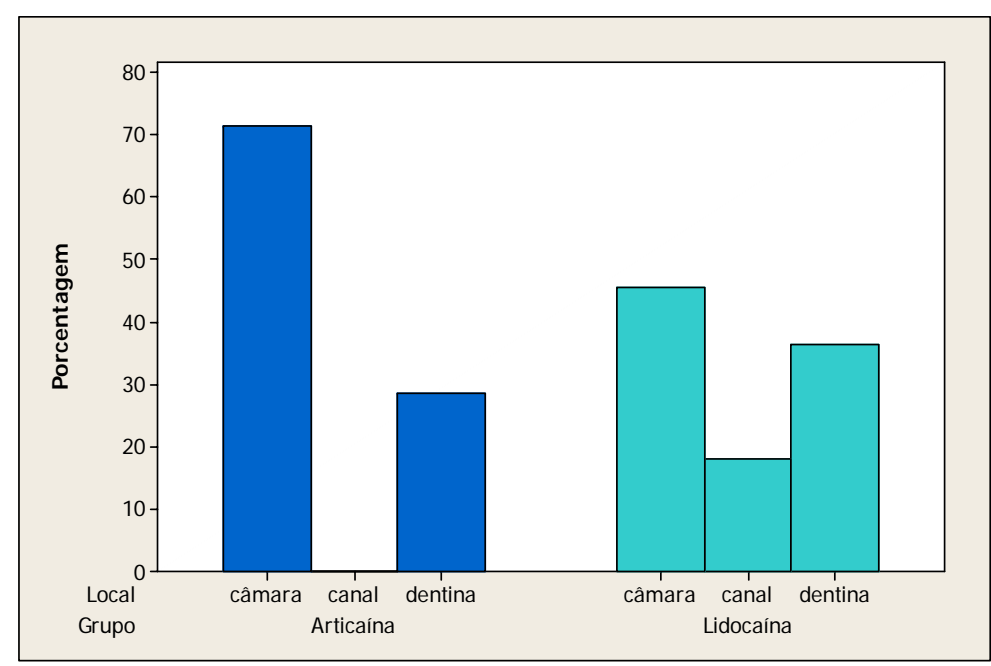

Figura 5.3 - Gráfico de barras das porcentagens de ocorrências das categorias dos locais onde a dor foi relatada nos grupos articaína e lidocaína - após bloqueio do NA 


\subsection{Categorias das repostas ao "pulptest" após a injeção complementar no ligamento periodontal}

Na Tabela 5.6 têm -se as distribuições de freqüências e porcentagens das respostas ao "pulptest" nos dois grupos após a injeção complementar no ligamento periodontal. Essas porcentagens estão representadas na Figura 5.4. Pelo teste exato de Fisher não foi detectada diferença significante entre as probabilidades de respostas negativas ao "pulptest" nos dois grupos.

Tabela 5.6 - Distribuições de freqüências e porcentagens das respostas ao "pulptest" nos dois grupos - após injeção complementar no ligamento periodontal

\begin{tabular}{c|cc|c}
\hline \multirow{2}{*}{ Grupo } & \multicolumn{2}{|c|}{ Resposta“pulptest" } & \multirow{2}{*}{ Total } \\
\cline { 2 - 3 } & Negativa & Positiva & \\
\hline Articaína & 4 & 3 & 7 \\
& $57,1 \%$ & $42,9 \%$ & $100,0 \%$ \\
Lidocaína & 10 & 1 & 11 \\
& $90,9 \%$ & $9,1 \%$ & $100,0 \%$ \\
\hline Total & 14 & 4 & 18 \\
& $77,8 \%$ & $22,2 \%$ & $100,0 \%$ \\
\hline
\end{tabular}

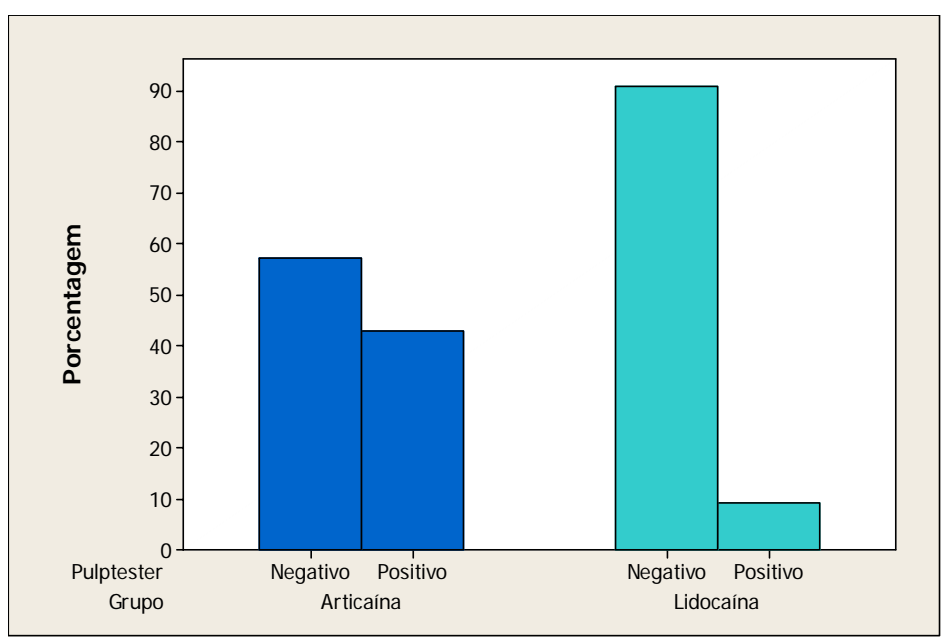

Figura 5.4-Gráfico de barras das porcentagens de ocorrências das categorias das respostas ao "pulptest" nos grupos articaína e lidocaína - após injeção no ligamento periodontal 


\subsection{Categorias da dor durante a finalização do procedimento de pulpectomia} após a injeção anestésica complementar no ligamento periodontal

A Tabela 5.7 apresenta as distribuições de freqüências e porcentagens da dor nos dois grupos após a anestesia complementar no ligamento periodontal. As porcentagens de ocorrência das categorias de dor estão representadas na Figura 5.5. Pelo teste exato de Fisher, não foi detectada diferença entre os dois grupos $(p>0,999)$.

Tabela 5.7 - Distribuições de freqüências e porcentagens da dor nos dois grupos - após injeção no ligamento periodontal

\begin{tabular}{c|cc|c}
\hline \multirow{2}{*}{ Grupo } & \multicolumn{2}{|c|}{ Dor } & \multirow{2}{*}{ Total } \\
\cline { 2 - 3 } Articaína & 2 & 5 & 7 \\
& $28,6 \%$ & $71,4 \%$ & $100,0 \%$ \\
Lidocaína & 2 & 9 & 11 \\
& $18,2 \%$ & $81,8 \%$ & $100,0 \%$ \\
\hline Total & 4 & 14 & 18 \\
& $22,2 \%$ & $77,8 \%$ & $100,0 \%$ \\
\hline
\end{tabular}

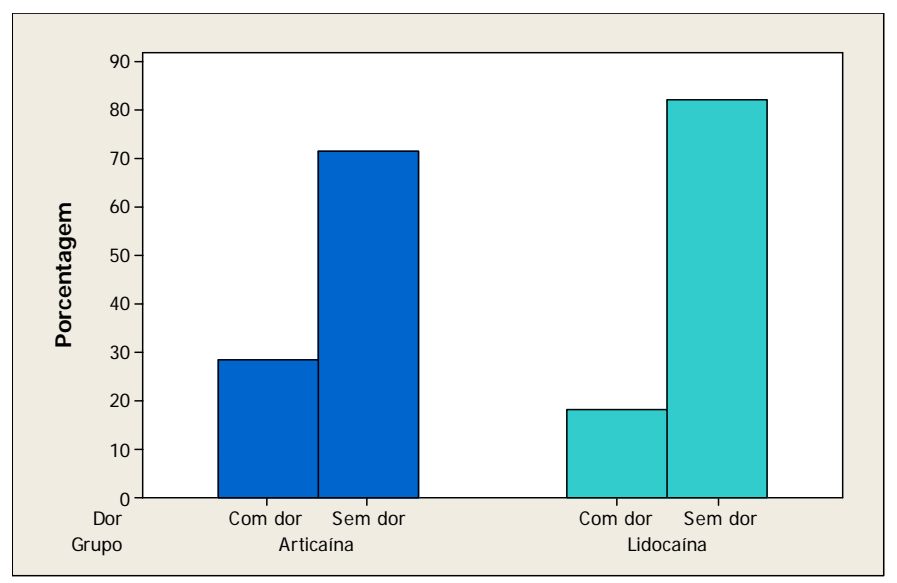

Figura 5.5-Gráfico de barras das porcentagens de ocorrências das categorias da dor nos grupos articaína e lidocaína - após injeção no ligamento periodontal 
5.10 Local onde a dor foi relatada após o bloqueio complementar no ligamento periodontal

Apenas 4 pacientes relataram dor após a anestesia complementar no ligamento periodontal: 2 no grupo da articaína, um relatou dor na câmara e outro no canal e 2 no grupo da lidocaína, um na câmara e outro no canal, similarmente. 


\section{DISCUSSÃO}

As amostras das soluções anestésicas não apresentaram diferenças significantes quanto ao gênero, a idade e o tipo do dente posterior (Tabela $5.1 \mathrm{e}$ Tabela 5.2). Portanto, o efeito do gênero, da idade e tipo do dente pode ser minimizado ou até desprezado entre as duas soluções.

O que se confirmou na presente pesquisa foi que, após 10 minutos do bloqueio do nervo alveolar inferior, todos os pacientes relataram anestesia profunda do lábio, ou seja, ela estava presente em 100\% dos pacientes em ambos os grupos.

No entanto, a presença da anestesia pulpar, isto é, a resposta negativa aos estímulos elétricos provocados pelo aparelho estimulador elétrico ("pulptest") após o bloqueio convencional do NAI esteve presente em 65\% (13/20) dos pacientes no grupo da articaína e em 70\% no grupo da lidocaína (14/20) (Tabela 5.3 e Figura 5.1).

Vale lembrar, que a resposta negativa dos pacientes à potência máxima (80) do verificador elétrico da polpa foi usada como critério para anestesia pulpar e a anestesia foi considerada bem sucedida quando duas leituras consecutivas foram obtidas após 10 minutos do bloqueio do NAI, imediatamente depois da confirmação da anestesia do lábio.

Portanto, apesar de todos os pacientes de ambos os grupos terem relatado sinal de anestesia profunda no lábio, o teste de vitalidade pulpar através do aparelho "pulptest" revelou que nem sempre a anestesia pulpar estava presente. Esse fato 
também é narrado por Claffey et al. (2004), Rosenberg et al. (2007) e Mikesell et al. (2005).

Essa informação é importante para o clínico menos informado, que acreditam que a anestesia do lábio, tipicamente usada como um indicador clínico do bloqueio do NAI, é uma garantia do sucesso da anestesia do bloqueio e consequentemente da polpa.

Um estudo recente de Kanaa et al. (2006), encontrou que a articaína foi significantemente melhor do que a lidocaína na infiltração mandibular no primeiro molar. Os autores consideraram como resultado de sucesso a ausência de vitalidade pulpar a dois estímulos máximos consecutivos do estimulador elétrico da polpa. $\mathrm{O}$ número de episódios de ausência de sensação ao estímulo máximo da polpa (80) nos $1^{\circ}$ molares durante o período do experimento (30 minutos) foram maiores para a articaína $(64,5 \%)$ do que para a lidocaína $(38,7 \%)$.

O resultado do índice de sucesso da anestesia pulpar determinado pelo "pulptest" (resposta negativa ao "pulptest") no nosso estudo foi de $65 \%$ para a articaína, muito próximo ao relatado no estudo de Kanaa et al. (2006), e o sucesso da lidocaína foi de $70 \%$, bastante diferente dos resultados deles, entretanto, eles utilizaram a anestesia infiltrativa mandibular.

Na verdade, o que interessa para o clínico que lida com a dor proveniente da pulpite irreversível não é se o dente vai ter uma resposta negativa ou positiva ao "pulptest"; na maioria das vezes, esse teste nem é utilizado, o importante é a ausência da dor durante os procedimentos endodônticos de rotina.

Sendo assim, constatou-se que após o bloqueio no NAI, uma porcentagem maior de indivíduos no grupo da lidocaína (55\% - 11/20) apresentou dor durante o procedimento de pulpectomia, e no grupo da articaína essa porcentagem foi menor 
(35 \% - 7/20). No entanto, essa diferença não foi significante (Tabela 5.4 e Figura $5.2)$.

Portanto, após o bloqueio do NAl, apesar da lidocaína ter tido maiores porcentagens de respostas negativas ao "pulptest" (70\% - 14/20) (Tabela 5.3), ela apresentou maiores porcentagens de dor (55\% - 11/20) (Tabela 5.4) durante 0 procedimento de pulpectomia, enquanto a articaína apresentou menor índice de resposta negativa ao "pulptest" (65\% - 13/20) (Tabela 5.3), mas uma menor porcentagem de dor (35\% - 7/20) (tabela 5.4) durante a pulpectomia.

Isto vai de encontro com os achados de Nusstein et al. (1998) que também indicaram que a presença da anestesia pulpar confirmada pelo "puptest" não garantiu a ausência da dor, pois afirmaram que $42 \%$ do total dos dentes posteriores por eles avaliados, responderam negativamente ao teste elétrico relatando dor durante procedimentos endodônticos.

Concordaram também com os resultados de Reisman et al. (1997), os quais afirmaram que dentes posteriores mandibulares diagnosticados com pulpite irreversível frequentemente não estão anestesiados depois do bloqueio do NAI, e também confirmaram que um teste elétrico negativo da polpa não é garantia de anestesia pulpar nas pulpites irreversíveis.

Por outro lado, Dreven et al. (1987) mostraram que uma resposta negativa a leitura 80 do "pulptest" garantiu anestesia pulpar e leituras menores do que 80 resultaram em dor durante procedimentos de restauração em dentes assintomáticos. Entretanto, acrescentaram que para dentes com pulpite irreversível, somente $73 \%$ tiveram anestesia clínica, isto é, não acusaram dor após terem respostas negativas ao estimulador pulpar elétrico, portanto $27 \%$ dos pacientes com pulpite irreversível requisitaram injeções anestésicas complementares. 
Essas semelhanças entre os resultados do presente trabalho e os de outros autores (Dreven et al., 1987; Reisman et al.1997; Nustein et al.,1998) em dentes com pulpite irreversível, nos levam a crer que dentes sintomáticos com inflamação pulpar não respondem de maneira confiável ao "pulptest".

Ainda pela análise da mesma tabela 5.4 e figura 5.2 pode-se também dizer que o sucesso do bloqueio do NAI que foi definido como nenhuma ou leve dor (escala verbal 0 ou 1) durante o procedimento de pulpectomia com a articaína (65\% - 13/20) foi melhor do que com a solução de lidocaína (45\% -9/20), no entanto, os testes estatísticos mostraram que essa diferença não foi significante.

Somente a pesquisa clínica de Clafey et al. (2004) comparou a articaína 4\% com a lidocaína 2\%, ambas associadas à epinefrina 1:100.000, em bloqueio convencional do nervo alveolar inferior em pacientes com pulpite irreversível. A porcentagem de sucesso para a articaína foi de 24\% (9 de 37) e para a lidocaína foi de 23\% (8 de 35) e não foi estatisticamente significante.

Os resultados dessa pesquisa quando comparados aos de Claffey et al. (2004) apresentaram índices de sucesso mais altos para a duas soluções, pois se conseguiu um índice de sucesso clínico (sem dor) de 65\% para a articaína (13 de 20) e de 45\% (9 de 20) para a lidocaína (Tabela 5.4 e figura 5.2).

Deve-se enfatizar que a metodologia da presente pesquisa e a de Clafey et al (2004) para definir o sucesso do bloqueio do NAI são idênticas, isto é; o sucesso foi definido como a capacidade de acessar e instrumentar o dente sem dor, ou dor leve. A única diferença foi a dose utilizada dos anestésicos, $3,6 \mathrm{ml}$ e 2,2 ml, respectivamente, para essa pesquisa e a de Claffey et al. (2004).

A dose proporcional a dois tubetes $(3,6 \mathrm{ml})$ foi utilizada em nossa metodologia, pois foi previamente mostrado que a dose de um único tubete $(1,8 \mathrm{ml})$ 
de anestésico local utilizado na injeção do bloqueio do NAl é efetiva somente em 30 a $80 \%$ dos pacientes com pulpite irreversível, conforme relatado por Rosenberg et al. (2007) e também por ser a dose habitualmente usada no Setor de Urgência. Assim sendo, uma dose proporcional a dois tubetes foi administrada na tentativa de compensar a baixa freqüência documentada na literatura para a anestesia pulpar profunda dos dentes mandibulares com pulpite irreversível usando uma só injeção.

No entanto, a suposição baseada em evidências clínicas de que uma dose aumentada (2 tubetes) do anestésico local pode ser mais efetiva, não é inteiramente apoiada na literatura. Patocnik e Bajrovic (1999) afirmaram que uma vez que o volume eficaz do anestésico local é alcançado nenhum beneficio adicional pode ser conseguido e um volume de $2,0 \mathrm{ml}$ de uma solução de lidocaína $2 \%$ com adrenalina parece ser satisfatório.

A literatura também afirma que a concentração de epinefrina dos tubetes anestésicos locais $(1: 50.000,1: 180.000$ e 1:100.000) não influenciaram na efetividade anestésica (DAGHER, YARED; MACHTOU,1997). Optou-se então pela concentração de 1:100.000 de epinefrina para ser utilizada nessa pesquisa por ser mais segura, principalmente em relação às alterações cardiovasculares, e com certeza a mais utilizada pela maioria dos profissionais em odontologia.

Como pode ser observado ainda na mesma tabela 5.4 e figura 5.2, após o bloqueio do NAI, 35\% dos pacientes do grupo da articaína, ou seja, 7 pacientes sentiram dor durante o procedimento de pulpectomia e 55\% do grupo da lidocaína, ou seja, 11 pacientes.

O local no qual o paciente sentiu dor durante o acesso na câmara pulpar foi anotado como na dentina, na câmara ou no canal. As distribuições de freqüências e 
porcentagens dos locais onde a dor foi relatada pelos pacientes nos dois grupos após o bloqueio do NAI podem ser vistas na Tabela 5.5 e Figura 5.3.

A dor na dentina foi relatada por 2 pacientes no grupo da articaína $(28,6 \%$ 2/7) e por 4 no grupo da lidocaína (36,4\% - 4/11). Quando a dor é relatada logo na dentina, com certeza, os clínicos terão uma maior dificuldade de entrar na polpa para administrar a injeção intrapulpar do que quando ela é relatada mais adiante na câmara ou no canal.

Pela observação dos resultados apresentados nessa pesquisa clínica, podese dizer que, com qualquer um dos anestésicos locais, o cirurgião-dentista poderá ter problemas para controlar a dor até conseguir uma abertura na câmara pulpar para realizar a injeção anestésica intrapulpar. Parece que a articaína apresentou um comportamento um pouco melhor em relação a dor na dentina, o que, talvez, pode ser extrapolado para uma maior profundidade da anestesia.

A dor relatada na câmara pulpar após o bloqueio do NAI foi a mais freqüente nos dois grupos, respectivamente, $71,4 \%(5 / 7)$ e 45,5 \% (5/11) para a articaína e lidocaína. A dor na câmara também é um problema ao clínico na realização da anestesia intrapulpar: ao introduzir a agulha para realizar a injeção intrapulpar, a dor será aguda e extremamente severa.

Portanto, quando a dor é relatada em ambos locais, dentina ou câmara, acarretarão dificuldades clínicas ao profissional. A diferença entre elas é que, a dor na câmara é aguda, insuportável, mas experimentada de uma só vez, enquanto a dor na dentina é menos aguda, mas contínua durante todo o procedimento do acesso de abertura do dente e intercalada na intensidade de leve a moderada e, às vezes, até severa. 
Segundo a opinião de alguns autores; a injeção intrapulpar é muito dolorosa e não é indicada como um método primário de anestesia (Walton e Abbott, 1981), o único emprego da anestesia intrapulpar é para os fracassos da anestesia inicial (MEECHAN, 2002).

Baseado em experiências clínicas pode-se acrescentar mais uma desvantagem para a anestesia intrapulpar: além da dor, a inabilidade freqüente de introduzir a agulha com subseqüente dificuldade em atingir a pressão necessária para que ela seja eficaz. Trabalhos já mostraram que a pressão em que a solução é injetada, é mais eficaz do que os efeitos da própria solução anestésica (BIRCHFIELD; ROSENBERG, 1975, VanGHELUWE et al., 1997)

Portanto, quando as anestesias infiltrativas locais e os bloqueios regionais não fornecerem o nível necessário de anestesia para controle da dor, outras técnicas complementares são preferíveis às anestesias intrapulpares.

Em contraste, a injeção no ligamento periodontal é bem menos dolorosa se for precedida pela injeção convencional do bloqueio do NAl e tem latência tão rápida e duração tão curta quanto a intrapulpar, o que para os procedimentos de pulpectomia em caráter de urgência é bom.

Além do que, é um método de fácil aplicação e não exige material apropriado, como é o caso da injeção intraóssea. Embora as seringas "especiais" para injeção no ligamento periodontal podem ser usada de forma eficaz e segura, geralmente, não são necessárias, como é relatado na literatura (MALAMED, 2005; MEECHAN, 2002; WALTONA; ABBOTT, 1981).

A injeção intraóssea é efetiva como anestesia complementar como foi confirmado por outros autores (Reisman et al., 1997; Parente et al., 1988; Nusstein et al. (1998), Bigby et al., 2006), mas em nossa opinião ela deveria ser usada 
somente se a injeção no ligamento periodontal falhar ou se a injeção intrapulpar for impossível de ser realizada.

A maior contra-indicação da injeção intróssea, talvez para a maioria dos clínicos, seria a necessidade de equipamento especial, que no caso seria também o problema do Setor de Urgência, assim como também devem ser de outras entidades de pronto atendimento. Existem outros equipamentos de maior utilidade e necessidade para serem adquiridos antes de um Stabident ${ }^{\circledR}$, por exemplo.

Um maior tempo para o atendimento de urgência, já que a técnica e o equipamento são mais complexos, além de possível dor pós-operatória devido à perfuração óssea, também são fatores a serem considerados em serviços de prontoatendimento ou mesmo nos encaixes das consultas de urgência na clínica particular quando a injeção intraóssea é utilizada.

Portanto, empregou-se a injeção no ligamento periodontal em nossa metodologia por acreditar que tenha uma maior aplicação clínica. É uma técnica simples, pode ser realizada com a mesmo seringa carpule utilizada na injeção anterior do bloqueio no NAI. Walton e Abbott (1981) garantem que pode ser admistrada até com a mesma agulha.

Os únicos inconvenientes da técnica de injeção no ligamento periodontal que foram constatados durante os experimentos clínicos da presente pesquisa foi o extravasamento da solução anestésica na cavidade bucal e possibilidade de fratura dos tubetes de vidro. O extravasamento, infelizmente, ocorreu em todos os pacientes e não tiveram conseqüência maior do que a reclamação do gosto amargo na boca pelos mesmos. Em um paciente ocorreu a fratura do tubete, o que pode causar certa apreensão ao paciente e operador e deve-se ter cautela, principalmente com os olhos e a possibilidade de deglutição do vidro diante desse acidente. Uma 
alternativa seria utilizar tubetes de plástico para realização da anestesia no ligamento periodontal.

Os resultados das respostas ao "pulptest" após a injeção no ligamento periodontal foram similares com os obtidos após o bloqueio do $\mathrm{NAI}$, ou seja, novamente a lidocaína apresentou um índice mais alto de respostas negativas ao "pulptest" (90,9\% - 10/11) enquanto a articáina apresentou um índice mais baixo (57,1\% - 4/7) e as diferenças não foram significantes (Tabela 5.6 e figura 5.4).

Quando foi dado prosseguimento ao procedimento de pulpectomia, após a injeção no ligamento periodontal, a freqüência para a dor do grupo da articaína foi de 28,6\% (2/7) e para o grupo da lidocaína de 18,2\% (2/11) (tabela 5.7 e Figura 5.5). Isso é o mesmo que dizer que a falha da injeção no ligamento periodontal foi de 28,6\% e 18,2\%, respectivamente, para a articáina e lidocaína. Portanto, dois pacientes do grupo da articáina e dois do grupo da lidocaína relataram dor após a injeção complementar no ligamento periodontal e essa diferença não foi significante.

Por um raciocínio contrário, ainda pela análise da Tabela 5.7, a injeção complementar no ligamento periodontal para o grupo da articaína obteve um índice de sucesso de 71,4\% (5/7) e para a lidocaína de 81,8\% (9/11).

O local em que foi relatada a dor nos dois grupos para os dois pacientes após a injeção do ligamento periodontal foi exatamente o mesmo isto é; um paciente sentiu dor na câmara e outro no canal.

Uma única pesquisa (Berlin et al., 2005) que comparou a articaína 4\% com a lidocaína 2\% em injeções no ligamento periodontal foi encontrada, porém foi realizada com um sistema de deposição anestésica computadorizada (Wand Plus ${ }^{\circledR}$ ), e a técnica foi primária e não complementar, diferente da metodologia aplicada 
nesse trabalho. Segundo os autores a frequência de sucesso para a articaína foi de 86\% e para a lidocaína de 74\%.

Ao se comparar os resultados do presente estudo com os de Berlin et al (2005), nota-se que a frequência de sucesso da injeção complementar no ligamento periodontal para a articaína foi mais baixa $(71,4 \%)$ e para a lidocaína foi mais alta (81,8\%), do que na técnica primária por eles utilizada.

Em resumo, na metodologia empregada nessa pesquisa clínica, o comportamento da lidocaína após a injeção complementar no ligamento periodontal foi melhor do que o da articáina, em relação à ausência de resposta ao "pulptest" e à dor. A articaína só se comportou melhor do que a lidocaína na ausência da dor após o bloqueio do nervo alveolar inferior. Entretanto, essas diferenças no comportamento entre as duas soluções não foram significantes em nenhuma das duas técnicas de injeção.

Portanto, mais uma vez, não se conseguiu provar, estatisticamente, a superioridade da articaína em relação à lidocaína em pesquisas clínicas. As duas soluções tiveram comportamentos semelhantes e foram ineficazes no controle da dor durante o tratamento da pulpite irreversível.

A metodologia utilizada na presente pesquisa clínica foi muito simples, útil e de fácil aplicação, principalmente no Setor de Urgência, e deverá ser continuada com as mesmas soluções anestésicas com a finalidade de um aumento da amostra. 


\section{CONCLUSÕES}

7.1 As duas soluções anestésicas se comportam de forma semelhante no tratamento de urgência da pulpite irreversível em dentes posteriores mandibulares.

7.2 Apesar da articaína apresentar maior eficácia clínica no bloqueio do nervo alveolar inferior e a lidocaína na injeção no ligamento periodontal, as diferenças não são significantes.

7.2 Nenhuma solução anestésica resultou em um índice de sucesso anestésico aceitável em pacientes com pulpite irreversível em dentes posteriores mandibulares. 


\section{REFERÊNCIAS ${ }^{1}$}

Alvares S, Alvares S. As várias situações patológicas do órgão dentário e a conduta clínica emergencial para equacioná-las. In: Alvares S, Alvares S. Emergências em endodontia. Diagnóstico e conduta clínica. São Paulo: Editora Santos; 1994. p. 25-65.

Berlin J, Nusstein J, Reader A, Beck M, Weaver J. Efficacy of articaine and lidocaine in a primary intraligamentary injection administered with a computer-controlled local anesthetic delivery system. Oral Surg Oral Med Oral Pathol Oral Radiol Endod 2005;99:361-6.

Bigby J, Reader A, Nusstein J, Becke M. Anesthetic efficacy of lidocaine/meperidine for inferior alveolar nerve blocks in patients with irreversible pulpitis. J Endod 2007;33:7-10.

Bigby J, Reader A, Nusstein J, Beck M, Weaver J. Articaine for supplemental intraosseous anesthesia in patients with irreversible pulpitis. $\mathrm{J}$ Endod 2006;32:1044-7.

Birchfield J, Rosenberg PA. Role of the anesthetic solution in intrapulpal anesthesia. J Endod 1975;1:26-7.

Childers M, Reader A, Nist R, Beck M, Meyers WJ. Anesthetic efficacy of the periodontal ligamente injection after an inferior alveolar nerve block. J Endod 1996;22:317-20.

Clafey E, Reader A, Nusstein J, Beck M, Weaver J. Anesthetic efficacy of articaine for inferior alveolar nerve blocks in patients wuth irreversible pulpitis. J Endod 2004;30:568-71.

Clark S, Reader A, Beck M, Meyers WJ. Anesthetic efficacy of the mylohyoid nerve block and combination inferior alveolar nerve block / mylohyoid nerve block. Oral Surg Oral Med Oral Pathol Oral Radiol Endod 1999;87:557-63.

\footnotetext{
${ }^{1}$ De acordo com Estilo Vancouver. Abreviatura de periódicos segundo base de dados MEDLINE.
} 
Costa GC, Tortamano IP, Rocha RG, Francischone CE, Tortamano N. Ondet and duration of articaine and lidocaine on maxillary infiltration. Quintessence Int 2005;36:197-201.

Daubländer M, Müller R, Lipp MDW. The incidence of complications associated with local anesthesia in dentistry. Anesth Prog 1997;44(4):132-41.

Daugher FB, Yared GM, Machtou P. An evaluuation of 2\% lidocaine with different concentrations of epinephrine foi inferior alveolar block. J Endod 1997;23:178-80.

Donaldson D, James-Perdok L, Craig BJ, Derkson GD, Richardson AS. A comparison of Ultracaine and Citanest in maxillary infiltration and mandibular nerve block. J Can Dent Assoc 1987;.53(1):38-42.

Edwards RW, Head TW. A clinical trial of intraligamentary anesthesia. J Dent Res 1989;68:1210-3.

Fisher LD; VanBelle G. Bioestatistics. New York:Jon Wiley \& Sons; 1993

Gregori C, Santos W. Anestesias intrabucais em odontologia. In: Gregori C. Cirurgia buco-dento-alveolar. São Paulo:Sarvier; 1996. p.62-82.

Haas DA, Lennon D. Local anesthetic use by dentists in Ontario. J Can Dent Assoc 1995;61(4):297-304.

Jakobs W, Ladwig B, Cichon P, Ortel R, Kirch W. Serum levels of articaine $2 \%$ and 4\% in children. Anesth Prog 1995;42(3/4):113-5.

Kanaa MB, Meechan JG, Corbett IP, Whiworth JM. Speed of injection influences efficacy of inferior alveolar nerve blocks: a double-blind randomized controlled trial in volunteers. J Endod 2006;32:919-23.

Kaufman E, Weinstein P, Milgrom P. Dificulties in achieving local anesthesia. J Am Dent Assoc 1984;108:205-8.

Kennedy S, Reader A, Nusstein J, Beck M, Weaver J. The significance of needle deflection in success of the inferior alveolar nerve block in patients with irreversible pulpitis. J Endod 2003;29:630-3. 
Lai TN, Lin CP, Kork SH, Yang PJ, Kuo YS, Lan WH, Chang HH. Evaluation of mandibular block using a standardized method. Oral Surg Oral Med Oral Pathol Oral Radiol Endod 2006;102:462-8.

Lemay H, Albert G, Hélie P, Dufour L, Gagnon P, Payant L, et al. Ultracaine en dentisterie opératoire conventionelle. J Can Dent Assoc 1984;9:703-8.

Malamed SF. Articaine vs. Lidocaine. J Am Dent Assoc 2000; 131(9):1248-50.

Malamed SF. What's new in local anesthesia? Anesth Prog 1992; 39(4/5):125-31.

Malamed SF . Técnicas de injeção suplementares. In: Malamed SF. Manual de anestesia local. Rio de Janeiro: Elsevier; 2005. p.255-68.

Malamed SF,. Gagnon S, Leblanc D. Articaine hydrochloride: a study of the safety of a new amide local anesthetic. J Am Dent Assoc 2001;132(2):177-185.

Meechan JG. Supplementary routes to local anaesthesia. Inter Endod J 2002;35:885-896

Meechan JG, Kanaa MD, Corbett IP, Steen IN, Whitworth JM. Pulpal anaesthesia for mandibular permanent first molar teeth: a double-blind randomized cross-over trial comparing buccal and buccal plus lingual infiltration injections in volunteers. Int Endod J 2006;39:764-9.

Meechan, JG. A comparison of ropivacaine and lidocaine with epinephrine for intraligamentary anesthesia. Oral Surg Oral Med Oral Pathol Oral Radiol Endod 2002;93:469-73.

Mikesel P, Nusstein J, Reader A, Beck M, Weaver J. A comparison of articaine and lidocaine for inferior alveolar blocks. J Endod 2005;31:265-70.

Nusstein J, Reacher A, Beck M. Anesthetic efficacy different volumes of lidocaine with epinephrine for inferior alveolar nerve blocks. Gen Dent 2002;50:372-5. 
Nusstein J, Reader A, Nist R, Beck M, Meyers WJ. Anesthetic efficacy of the supplemental intraosseous injection of $2 \%$ lidocaine with 1:100.000 epinephrine in irreversible pulpitis. J Endod 1998;24:487-91.

Oliveira PC, Volpato MC, Ramacciato LC, Ranali J. Articaine and lignocaine in infiltration anaesthesia: a pilot study. Br Dent J 2004; 197:45-6.

Oertel R, Rahn R, Kirch W. Clinical pharmacokinetics of articaine. Clin Pharmacokinet 1997;33(6):417-25.

Parente SA, Anderson RW, Herman WW, Kimbrough F, Weller N. Anesthetic efficacy of the supplemental intraosseous injection for teeth with irreversible pulpitis. J Endod 1998;24:826-8.

Pashley DH. Systemic effects of intraligamental injections. J Endod 1986;12;501-4.

Patocnik I, Bajrovic F. Failure of inferior alveolar nerve block in endodontics. Endod Dent Traumatol 1999;15:247-51.

Reisman D, Reader A, Nist R, Beck M, Weaver J. Anesthetic efficacy of the supplemental intraosseous injection of $3 \%$ mepivacaine in irreversible pulpitis. Oral Surg Oral Med Oral Pathol Oral Radiol Endod 1997;84:676-82.

Rosenberg PA, Amin KG, Zibari Y, Lin LM. Comparison of 4\% articaine with 1:100.000 epinephrine and 2\% lidocaine with 1:100.000 epinephrine when used as a supplemental anesthetic. J Endod 2007;33:403-5.

Schleder JR, Reader A, Beck M, Meyers WJ. The periodontal ligament injection: a comparison of $2 \%$ lidocaine, $3 \%$ mepivacaine, and 1:100,000 epinephrine to $2 \%$ lidocaine with 1:100,000 Epinephrine in human mandibular premolars. J Endod 1988;14:397- 404.

Schertzer ER; Malamed SF. Articaine vs.lidocaine. J Am Dent Assoc 2000;131:124850.

Taintor JF, Biesterfeld RC. Reliable local anesthesia in emergency treatment. J Tenn Dent Assoc 1989;69:18-21. 
Tófoli GR, Ramacciato JC, Oliveira PC, Volpato MC, Groppo FC, Ranali J. Comparison of effectiveness of articaine associated with 1;100.00 or 1:200.000 epinefphrine in inferior alveolar nerve block. Anesth Prog 2003;50:164-8.

Vahatalo $\mathrm{k}$, Antila $\mathrm{H}$, Lehtinen R. Articaine and lidocaine for maxillary infiltration anesthesia. Anesth Prog 1993; 40:114-6.

VanEeden SP, Patel MF. Prolonged paraesthesia following inferior alveolar nerve block using articaine. Br J Oral Maxillofac Surg 2002;40(6):519-20.

VanGheluwe J, Walton R. Intrapulpal injection.factors related to effectiveness. Oral Surg Oral Med Oral Pathol 1997;83;38-40.

Walton RE, Abbott BJ. Periodontal ligament injection: a clinical evaluation. J Am Dent Assoc 1981;103: 571-575.

Walton RE, Torabinejad M. Managing local anesthesia problems in the endodontic patient. J Am Dent Assoc 1992;123:97-102.

Weinstein P. Milgrom P, Kaufman E, Fiset I, Ramsey D. Patient perception of failure to achieve optimal local anesthesia. Gen Dent 1985;33:218-20.

Yagiela JA. Anestésicos locais. In: Yagiela JA, Neidle, EA, Dowd FJ. Farmacologia e terapêutica para dentistas. $4^{\mathrm{a}}$ ed. Rio de Janeiro: Mosby; 1998. cap. 17, p. 206-22. 


\section{Grupo 2- lidocaína}

\section{APÊNDICE B}

A idade, gênero, o número do dente posterior, categoria da resposta ao "pulptest", intensidade da dor, local da dor, sucesso do bloqueio, resposta ao "pulptest", intensidade da dor, local, sucesso da injeção no ligamento periodontal (PDL), presença da anestesia no lábio de cada paciente inseridos em uma planilha do programa Microsoft Excel.

\begin{tabular}{|c|c|c|c|c|c|c|c|c|c|c|c|c|}
\hline Paciente & Idade & Gênero & Ndente & Pulptest & Dor & Local & $\begin{array}{l}\text { Sucesso } \\
\text { Bloqueio } \\
\end{array}$ & Pulptest & Dor & Local & $\begin{array}{c}\text { Sucesso } \\
\text { PDL }\end{array}$ & $\begin{array}{c}\text { anes/láb- } \\
10 \text { (min) }\end{array}$ \\
\hline 1 & 19 & $M$ & 36 & $P$ & 0 & & $\mathrm{~S}$ & & & & & $\mathrm{P}$ \\
\hline 2 & 32 & $\mathrm{~F}$ & 47 & $P$ & 1 & dent/câmara & $\mathrm{S}$ & & & & & $P$ \\
\hline 3 & 45 & $\mathrm{~F}$ & 36 & $\mathrm{~N}$ & 0 & & $\mathrm{~S}$ & & & & & $\mathrm{P}$ \\
\hline 4 & 25 & $\mathrm{~F}$ & 47 & $\mathrm{~N}$ & 1 & câmara & $\mathrm{S}$ & & & & & $\mathrm{P}$ \\
\hline 5 & 18 & $\mathrm{~F}$ & 36 & $\mathrm{~N}$ & 0 & & $\mathrm{~S}$ & & & & & $\mathrm{P}$ \\
\hline 6 & 26 & $M$ & 36 & $\mathrm{~N}$ & 1 & canal & $\mathrm{S}$ & & & & & $\mathrm{P}$ \\
\hline 7 & 35 & $M$ & 36 & $\mathrm{~N}$ & 0 & & $\mathrm{~S}$ & & & & & $P$ \\
\hline 8 & 50 & $\mathrm{~F}$ & 45 & $\mathrm{~N}$ & 0 & & $\mathrm{~S}$ & & & & & $\mathrm{P}$ \\
\hline 9 & 48 & $\mathrm{~F}$ & 45 & $\mathrm{~N}$ & 0 & & $\mathrm{~S}$ & & & & & $P$ \\
\hline 10 & 23 & $\mathrm{~F}$ & 36 & $\mathrm{~N}$ & 2 & câmara & $\mathrm{N}$ & $\mathrm{N}$ & 2 & canal & $\mathrm{N}$ & $\mathrm{P}$ \\
\hline 11 & 31 & $\mathrm{~F}$ & 38 & $\mathrm{P}$ & 3 & câmara & $\mathrm{N}$ & $\mathrm{N}$ & 3 & camara & $\mathrm{N}$ & $\mathrm{P}$ \\
\hline 12 & 26 & $\mathrm{~F}$ & 47 & $\mathrm{~N}$ & 2 & dentina & $\mathrm{N}$ & $\mathrm{N}$ & 0 & & $\mathrm{~S}$ & $P$ \\
\hline 13 & 20 & $\mathrm{~F}$ & 36 & $\mathrm{~N}$ & 2 & dentina & $\mathrm{N}$ & $\mathrm{N}$ & 0 & & $\mathrm{~S}$ & $P$ \\
\hline 14 & 49 & $\mathrm{~F}$ & 38 & $\mathrm{P}$ & 2 & câmara & $\mathrm{N}$ & $\mathrm{N}$ & 0 & & $S$ & $\mathrm{P}$ \\
\hline 15 & 44 & $\mathrm{~F}$ & 47 & $\mathrm{~N}$ & 3 & câmara & $\mathrm{N}$ & $\mathrm{N}$ & 0 & & $S$ & $\mathrm{P}$ \\
\hline 16 & 19 & $\mathrm{~F}$ & 45 & $P$ & 3 & canal & $\mathrm{N}$ & $\mathrm{N}$ & 0 & & $\mathrm{~S}$ & $\mathrm{P}$ \\
\hline 17 & 34 & $M$ & 46 & $\mathrm{~N}$ & 2 & canal & $\mathrm{N}$ & $P$ & 0 & & $S$ & $P$ \\
\hline 18 & 50 & $\mathrm{~F}$ & 47 & $\mathrm{~N}$ & 2 & dentina & $\mathrm{N}$ & $\mathrm{N}$ & 0 & & $S$ & $\mathrm{P}$ \\
\hline 19 & 26 & $M$ & 46 & $\mathrm{P}$ & 2 & dentina & $\mathrm{N}$ & $\mathrm{N}$ & 0 & & $\mathrm{~S}$ & $\mathrm{P}$ \\
\hline 20 & 30 & $\mathrm{M}$ & 45 & $\mathrm{~N}$ & 2 & câmara & $\mathrm{N}$ & $\mathrm{N}$ & 1 & canal & $\mathrm{S}$ & $\mathrm{P}$ \\
\hline
\end{tabular}

Legenda

P (pulptest)-Positivo

$\mathrm{N}$ (pulptest)-Negativo

$\mathrm{S}$ (Sucesso bloqueio)-Sim

(Sucesso bloqueio-Não

P (Anestesia no lábio aos 10 minutos)-Presente 


\section{Grupo1 - articaína}

APÊNDICE A

A idade, gênero, o número do dente posterior, categoria da resposta ao "pulptest", intensidade da dor, local da dor, sucesso do bloqueio, resposta ao "pulptest", intensidade da dor, local, sucesso da injeção no ligamento periodontal (PDL), presença da anestesia no lábio de cada paciente inseridos em uma planilha do programa Microsoft Excel.

\begin{tabular}{|c|c|c|c|c|c|c|c|c|c|c|c|c|}
\hline Paciente & Idade & Gênero & Ndente & Pulptester & Dor & Local & $\begin{array}{l}\text { Sucesso } \\
\text { Bloqueio } \\
\end{array}$ & Pulptester & Dor & Local & $\begin{array}{c}\text { Sucesso } \\
\text { PDL }\end{array}$ & anes/láb-10 \\
\hline & 30 & $M$ & 36 & $\begin{array}{c}\text { Negativo } \\
\text { (N) }\end{array}$ & 0 & & . & & & & & Presente \\
\hline $\begin{array}{l}1 \\
2\end{array}$ & 47 & $\mathrm{~F}$ & 36 & $\mathrm{~N}$ & 0 & & S & & & & & $\begin{array}{l}\text { Presente } \\
\text { P }\end{array}$ \\
\hline 3 & 34 & M & 37 & $\mathrm{~N}$ & 0 & & $\mathrm{~S}$ & & & & & $P$ \\
\hline 4 & 50 & $\mathrm{~F}$ & 46 & $\mathrm{~N}$ & 0 & & $\mathrm{~S}$ & & & & & $\mathrm{P}$ \\
\hline 5 & 18 & M & 37 & $\mathrm{~N}$ & 0 & & $\mathrm{~S}$ & & & & & $P$ \\
\hline 6 & 27 & $\mathrm{~F}$ & 46 & $\mathrm{~N}$ & 0 & & $\mathrm{~S}$ & & & & & $\mathrm{P}$ \\
\hline 7 & 45 & $\mathrm{~F}$ & 47 & $\mathrm{~N}$ & 0 & & $\mathrm{~S}$ & & & & & $P$ \\
\hline 8 & 19 & M & 37 & $\mathrm{~N}$ & 0 & & $\mathrm{~S}$ & & & & & $\mathrm{P}$ \\
\hline 9 & 24 & M & 37 & $\mathrm{~N}$ & 0 & & $\mathrm{~S}$ & & & & & $P$ \\
\hline 10 & 22 & M & 36 & $\mathrm{~N}$ & 1 & canal & $\mathrm{S}$ & & & & & $P$ \\
\hline 11 & 26 & $\mathrm{~F}$ & 38 & $\mathrm{~N}$ & 1 & dent/canal & $\mathrm{S}$ & & & & & $P$ \\
\hline 12 & 24 & M & 37 & $\mathrm{~N}$ & 1 & câm/canal & $\mathrm{S}$ & & & & & $\mathrm{P}$ \\
\hline 13 & 18 & $\mathrm{~F}$ & 36 & $N$ & 2 & dentina & Não (N) & $\mathrm{N}$ & 3 & camara & $\mathrm{N}$ & $\mathrm{P}$ \\
\hline 14 & 31 & $\mathrm{~F}$ & 46 & Positivo (P) & 2 & câmara & $\mathrm{N}$ & $\mathrm{N}$ & 0 & & $\mathrm{~S}$ & $\mathrm{P}$ \\
\hline 15 & 29 & M & 37 & $P$ & 2 & câmara & $\mathrm{N}$ & $\mathrm{N}$ & 0 & & $\mathrm{~S}$ & $\mathrm{P}$ \\
\hline 16 & 39 & $\mathrm{~F}$ & 46 & $\mathrm{P}$ & 3 & câmara & $\mathrm{N}$ & $\mathrm{N}$ & 0 & & $\mathrm{~S}$ & $\mathrm{P}$ \\
\hline 17 & 30 & M & 36 & $P$ & 2 & câmara & $\mathrm{N}$ & P & 1 & canal & S & $P$ \\
\hline 18 & 30 & F & 46 & $P$ & 2 & câmara & $\mathrm{N}$ & $\mathrm{P}$ & 0 & & $\mathrm{~S}$ & $P$ \\
\hline 19 & 19 & M & 37 & P & 0 & & $\mathrm{~S}$ & & & & & $P$ \\
\hline 20 & 32 & $\mathrm{~F}$ & 45 & $\mathrm{P}$ & 2 & dentina & $\mathrm{N}$ & $\mathrm{P}$ & 2 & canal & $\mathrm{N}$ & $\mathrm{P}$ \\
\hline
\end{tabular}

$\mathrm{P}$ (pulptest)-Positivo

$\mathrm{N}$ (pulptest)-Negativo

$\mathrm{S}$ (Sucesso bloqueio)-Sim

N (Sucesso bloqueio)-Não

P (Anestesia no lábio aos 10 minutos)-Presente 


\section{ANEXO 1}

Ficha de Anamnese

Nome

RG

Endereço

CEP Bairro

Tel.:

Data nasc. Estado civil Profissão Cor

Anamnese: Data

1) Você está sentindo algum tipo de dor ou desconforto no momento?

2)Você está fazendo algum tratamento médico atualmente? Motivo?

3)Está tomando alguma medicação? Qual(is)?

4) Você já teve alguma reação alérgica a algum medicamento,alimento, enxofre ou outro produto?

5) Você já se submeteu a anestesia local?

6) Você teve algum tipo de reação adversa à essa anestesia?

7) Você já foi submetido à alguma cirurgia ou foi hospitalizado?

8) Você já recebeu transfusão de sangue?

9) Já teve hemorragia?

11) Qual (is) destes sintomas ou doenças você tem ou já teve? Hipertensão pneumonia diabetes

Hipotensão tuberculose perda de peso $(+5 \mathrm{~kg})$

Dor de cabeça sinusite

Asma febre reumática ganho de peso $(+5 \mathrm{~kg})$

Bronquite gastrite hepatite ou icterícia

Epilepsia anemias distúrbios hepáticos Problemas renais desmaio doenças venéreas distúrbios psíquicos

12) Se sente cansado com freqüência? Sente falta de ar?

13) Tem dificuldade de respirar quando este deitado?

13) Sente dor no peito depois de esforço ou sob tensão?

14) Quando mediu a sua PA pela última vez? Como estava?

15) Tem alguma doença cardíaca congênita ou adquirida (ex.mal de chagas)?

16) Tem ou teve algum sintoma ou doença não citado acima?

17) Você esta grávida?

18) Você fuma?

19)Você faz uso de bebidas alcoólicas ou outras drogas?

20) Você ingeriu bebida alcoólica nas últimas 4 horas?

$\mathrm{Eu}$, declaro para todos os fins legais que prestei esclarecimentos corretos sobre meu estado de saúde, nada omitindo no questionário que respondi.

Ass. data 1 
ANEXO 2

Paciente: data

Solução

(.....) Articaína

(.....) Lidocaína

Técnica

(...) bloqueio regional

(...) bloqueio regional, com complementação da injeção PDL

Dente tratado:

Fase de diagnóstico

\begin{tabular}{|l|l|l|l|}
\hline Dentes & TV1 & TV2 & AP \\
\hline Canino & & & \\
\hline Dente adjacente & & & \\
\hline Dente-pulpectomia & & & \\
\hline
\end{tabular}

Nessa fase será apresentada a escala numérica verbal de dor aos pacientes

Escala numérica para avaliação da dor:

\begin{tabular}{|c|c|c|c|}
\hline $\mathbf{0}$ & $\mathbf{1}$ & $\mathbf{2}$ & $\mathbf{3}$ \\
\hline $\begin{array}{l}\text { Ausência } \\
\text { de dor }\end{array}$ & Dor fraca / & Moderada/ severa /Intensa \\
\hline
\end{tabular}

Fase anestésica 1

Término da anestesia hs

Anestesia do lábio ( ) Presente ( ) Ausente

Tempo:10:00 min / Hora:

hs

Anestesia pulpar

\begin{tabular}{|l|l|l|l|}
\hline Dentes & TV1 & TV2 & AP \\
\hline Canino & & & \\
\hline Dente adjacente & & & \\
\hline Dente-pulpectomia & & & \\
\hline
\end{tabular}


Pulpectomia

Marcar um X na coluna correspondente ao número que o paciente atribui à dor.

Escala numérica verbal de dor:

\begin{tabular}{|l|l|l|l|l|}
\hline \multicolumn{1}{|c|}{ Local } & $\mathbf{0}$ & $\mathbf{1}$ & $\mathbf{2}$ & $\mathbf{3}$ \\
\hline Dentina & & & & \\
\hline câmara pulpar & & & & \\
\hline Canal & & & & \\
\hline
\end{tabular}

Sucesso ( ) Falha ( )

Fase anestésica 2:

Está na dependência da falha da fase anestésica 1.

Anestesia pulpar

\begin{tabular}{|l|l|l|l|}
\hline Dentes & TV1 & TV2 & AP \\
\hline Canino & & & \\
\hline Dente adjacente & & & \\
\hline Dente-pulpectomia & & & \\
\hline
\end{tabular}

\section{Pulpectomia}

Marcar um X na coluna correspondente ao número que o paciente atribui à dor.

Escala numérica verbal de dor:

\begin{tabular}{|l|l|l|l|l|}
\hline \multicolumn{1}{|c|}{ Local } & $\mathbf{0}$ & $\mathbf{1}$ & $\mathbf{2}$ & $\mathbf{3}$ \\
\hline Dentina & & & & \\
\hline câmara pulpar & & & & \\
\hline Canal & & & & \\
\hline
\end{tabular}

Sucesso ( ) Falha ( ) 


\section{ANEXO 3 \\ UNIVERSIDADE DE SÃO PAULO \\ FACULADE DE ODONTOLOGIA}

\section{TERMO DE CONSENTIMENTO LIVRE ESCLARECIDO}

TíTULO: Eficácia anestésica da articaína e da lidocaína em pacientes com pulpite irreversível PESQUISADOR: Isabel Peixoto Totamano

\section{Jusficativa da Pesquisa:}

A anestesia que vamos utilizar é freqüentemente realizada em odontologia quando se realiza procedimentos em dentes posteriores da mandíbula. No entanto, nem sempre esse tipo de anestesia na mandíbula é eficiente, principalmente quando se trata de dentes com inflamação em seu nervo, que denominamos de pulpite irreversível. Existe um anestésico muito utilizado em odontologia que é a lidocaína e, atualmente, um outro anestésico local foi introduzido no Brasil, portanto, queremos compará-lo à lidocaína para ver se ele apresenta algumas vantagens.

\section{Objetivos:}

-Comparar a eficácia anestésica da articaína 4\% com epinefrina na concentração de 1: 100.000 e da lidocaína $2 \%$ com a mesma concentração de epinefrina na anestesia realizada para executar os procedimentos para o alívio da dor (pulpectomia) nos dentes posteriores inferiores com inflamação do nervo, verificando o sinal da anestesia (entorpecimento) do lábio, presença da anestesia no nervo do dente e a ausência de dor durante o procedimento realizado de urgência.

-Comparar a eficácia anestésica da articaína 4\% com epinefrina na concentração de 1: 1000.000 e da lidocaína $2 \%$ com a mesma concentração de epinefrina na anestesia em produzir anestesia complementar para que o procedimento de pulpectomia possa ser terminado sem dor, caso a anestesia anterior convecional falhar.

\section{Material e Método:}

Seleção de voluntários - Serão selecionados 40 voluntários com pressão arterial normal, e saúde normal, de ambos os sexos, de 18 a 50 anos de idade. Deverão apresentar um dente posterior inferior com inflamação do nervo e um dente posterior ao lado dele, como um dente canino do outro lado, livre de cárie ou presença de restaurações extensas ou de doença na gengiva adjacente ao dente. Nesses dentes serão realizados os testes elétricos para avaliar se o efeito anestésico local está presente e determinar o tempo em que esse efeito anestésico vai terminar (dentro de um período de 60 minutos). O dente que será realizado o curativo de pulpectomia (remoção do nervo inflamado) é o dente que está com dor. Os procedimentos realizados, caso o senhor (a) aceite participar da pesquisa, serão exatamente os que já são realizado pelo Setor de Urgência para o alívio da dor. A diferença é que além do teste térmico com frio, que normalmente é realizado como procedimento de 
rotina durante o exame clínico no dente com dor, serão realizados também testes elétricos. O teste elétrico no dente dá uma sensação de formigamento, um choque muito leve, e assim que o cirurgiãodentista for avisado, removerá imediatamente a ponta ativa do aparelho que está em contato com o dente.

Não serão aceitas pacientes gestantes, alérgicos às substância utilizadas na pesquisa e portadores de doenças cardíacas e pressão alta. Os testes elétricos serão realizados imediatamente antes do início do curativo de pulpectomia e por 60 minutos após. $O$ aparelho utilizado para a realização dos testes elétricos será o Vitality Scaner $2006 \AA$, SybroEndo, CA, USA, também conhecido como "pulptest", cuja a ponta (sonda) será encostada na coroa do dente que está com dor, no dente ao lado e no canino do outro lado. Anestésicos utilizados:

LIDOCAÍNA 100® (DEFL) - cloridrato de lidocaína 2\% associado à epinefrina 1:100.000

ARTICAINE 100® (DFL) - cloridrato de articaína 4\% associado à epinefrina 1:100.000

\section{Local da realização do experimento:}

Setor de Urgência da Faculdade de Odontologia da Universidade de São Paulo

\section{Benefícios do experimento:}

A pesquisa permitirá avaliar qual das soluções apresenta maior eficácia clínica. Outro benefício direto ao paciente será a realização do curativo de pulpectomia para o alívio da dor, o qual será realizado mesmo se o paciente não quiser participar da pesquisa.

\section{Desconforto ou risco esperado:}

Poderá ocorrer desconforto (leve formigamento, um choque) decorrente da aplicação do teste elétrico. A dor devido à punctura (picada) e a injeção do anestésico local também poderão ocorrer e esta deverá ser minimizada através da aplicação do gel tópico de anestésico local antes da punctura. Caso necessitar de anestesia complementar que será a inserção da agulha na gengiva adjacente ao dente poderá ocorrer uma maior sensibilidade dolorosa do que a anestesia anterior. Entretanto essa dor também será amenizada pelo efeito anestésico da injeção anterior.

\section{Informações:}

O paciente voluntário terá garantia de que receberá respostas às quaisquer perguntas ou esclarecimento dos procedimentos.

\section{Riscos, benefícios e outros relacionados à pesquisa:}

Como será realizada várias perguntas em relação à história médica dos pacientes voluntários, principalmente em relação a sua pressão arterial, doença cardiovascular, alergia e medicamentos utilizados será muito difícil ocorrer alguma complicação decorrente da anestesia, já que o uso desse anestésicos é bastante seguro, principalmente em indivíduos saudáveis e nas doses utilizadas. Porém se algo ocorrer temos condições de prestar os primeiros socorros na ocorrência de uma emergência médica e eventualmente também podemos contar com uma enfermeira e o Pronto Socorro do Hospital Universitário.

Após o atendimento de urgência, os pacientes serão encaminhados para a realização do tratamento endodôntico na própria clínica da FOUSP e se houver a necessidade de nova intervenção em caráter de urgência (dor ou desconforto pós-operatório|), a pesquisadora a qualquer momento pelo celular 93596995 e os docentes da urgência estarão a disposição dentro do horário de atendimento. 


\section{Retirada do consentimento:}

O voluntário tem liberdade de retirar seu consentimento a qualquer momento e deixar de participar do estudo e, ainda assim poder receber os benefícios da pesquisa.

\section{Sigilo:}

Toda e qualquer informação obtida na pesquisa será confidencial.

\section{Disponibilidde:}

Estamos à disposição para qualquer informação ou queixa por parte do paciente, podendo ligar para os seguintes telefones: 3091-7813 ou 3091-8030 (Profa. Dra. Isabel)

\section{Consentimento Livre Esclarecido por escrito:}

EU $R G$ certifico que tendo

lido as informações e sido suficientemente esclarecido sobre os ítens da pesquisa, Eficácia anestésica da artícaina e da lidocaína em pulpite irreversível pela Profa. Dra. Isabel Peixoto Tortamano estou plenamente de acordo com a realização do experimento. Assim autorizo a execução do trabalho de pesquisa, exposto acima, com a minha colaboração espontância.

Assinatura do paciente

Assinatura da pesquisadora

Prof. Dra. Isabel Peixoto Tortamano 
( $2^{\mathrm{a}}$ via - Pesquisador)

Consentimento Livre Esclarecido por escrito:

EU RG certifico que tendo lido as informações e sido suficientemente esclarecido sobre os ítens da pesquisa, Eficácia anestésica da artícaina e da lidocaína em pulpite irreversível pela Profa. Dra. Isabel Peixoto Tortamano, estou plenamente de acordo com a realização do experimento. Assim autorizo a execução do trabalho de pesquisa, exposto acima, com a minha colaboração espôntania.

Assinatura do paciente

Assinatura pesquisadora

Prof. Dra. Isabel Peixoto Tortamano 